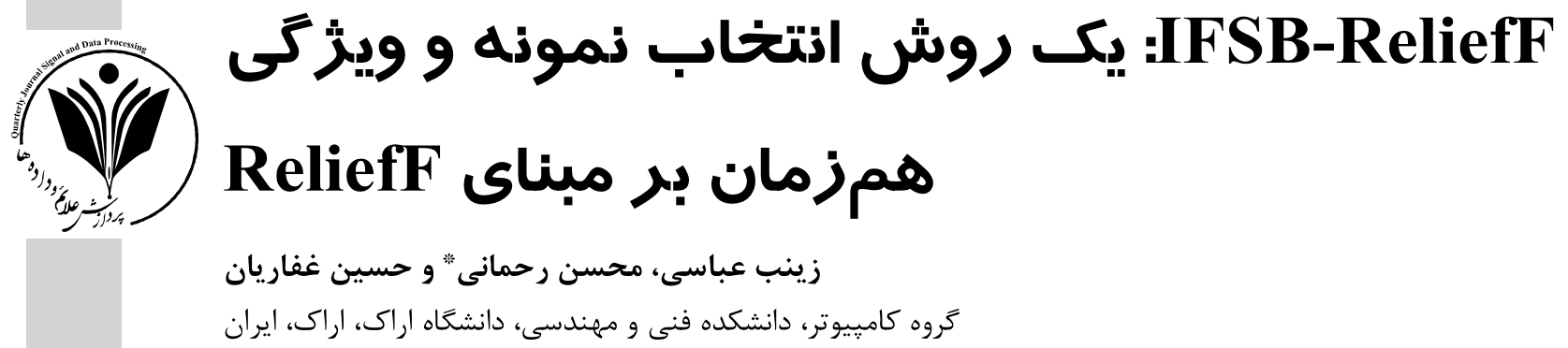

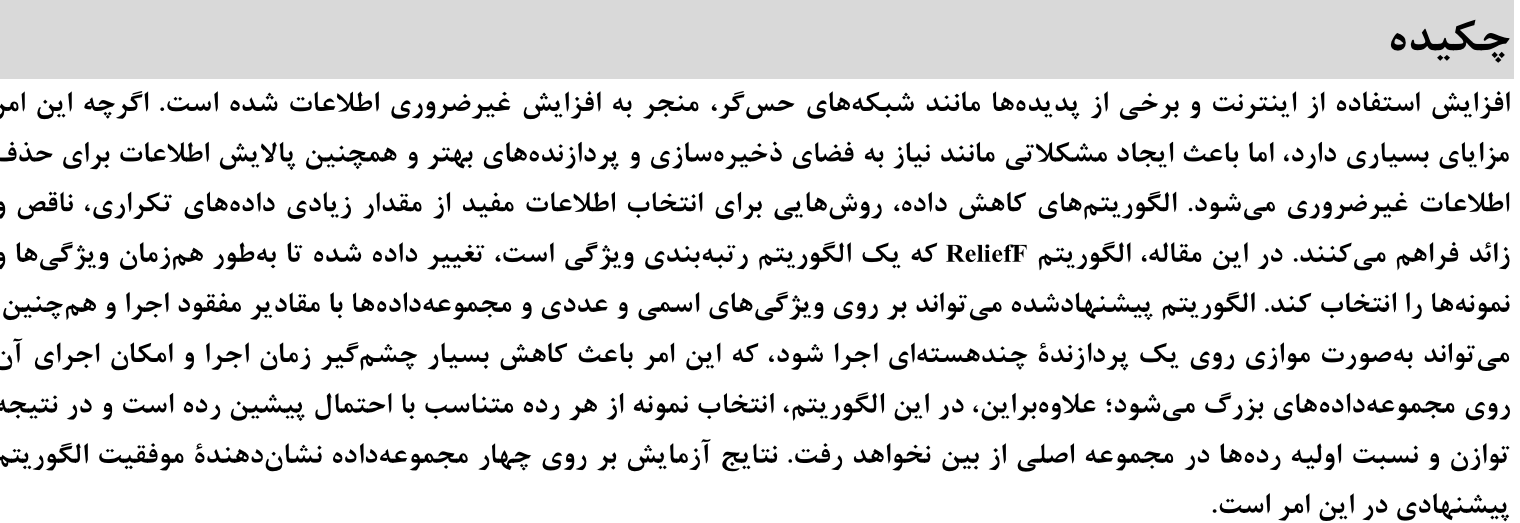

وازَّان كليدى: كاهش دادهها، انتخاب نمونه، انتخاب ويزگىى، ReliefF.

\title{
IFSB-ReliefF: A New Instance and Feature Selection Algorithm Based on ReliefF
}

\author{
Zeinab Abbasi, Mohsen Rahmani* \& Hossein Ghafarian \\ Computer Department, faculty of engineering, Arak University, Arak, Iran
}

\begin{abstract}
Increasing the use of Internet and some phenomena such as sensor networks has led to an unnecessary increasing the volume of information. Though it has many benefits, it causes problems such as storage space requirements and better processors, as well as data refinement to remove unnecessary data. Data reduction methods provide ways to select useful data from a large amount of duplicate, incomplete and redundant data. These methods are often applied in the pre-processing phase of machine learning algorithms. Three types of data reduction methods can be applied to data: 1. Feature reduction.2. Instance reduction: 3 . Discretizing feature values.

In this paper, a new algorithm, based on ReliefF, is introduced to decrease both instances and features. The proposed algorithm can run on nominal and numeric features and on data sets with missing values. In addition, in this algorithm, the selection of instances from each class is proportional to the prior probability of classes. The proposed algorithm can run parallel on a multi-core $C P U$, which decreases the runtime significantly and has the ability to run on big data sets.

One type of instance reduction is instance selection. There are many issues in designing instance selection algorithms such as representing the reduced set, how to make a subset of instances, choosing


distance function, evaluating designed reduction algorithm, the size of reduced data set and determining the critical and border instances. There are three ways of creating a subset of instances. 1) Incremental. 2) Decremental. 3) Batch. In this paper, we use the batch way for selecting instances. Another important issue is measuring the similarity of instances by a distance function. We use Jaccard index and Manhattan distance for measuring. Also, the decision on how many and what kind of instances should be removed and which must remain is another important issue. The goal of this paper is reducing the size of the stored set of instances while maintaining the quality of dataset. So, we remove very similar and non-border instances in terms of the specified reduction rate.

The other type of data reduction that is performed in our algorithm is feature selection. Feature selection methods divide into three categories: wrapper methods, filter methods, and hybrid methods. Many feature selection algorithms are introduced. According to many parameters, these algorithms are divided into different categories; For example, based on the search type for the optimal subset of the features, they can be categorized into three categories: Exponential Search, Sequential Search, and Random Search. Also, an assessment of a feature or a subset of features is done to measure its usefulness and relevance by the evaluation measures that are categorized into various metrics such as distance, accuracy, consistency, information, etc.

ReliefF is a feature selection algorithm used for calculating a weight for each feature and ranking features. But this paper is used ReliefF for ranking instances and features. This algorithm works as follows: First, the nearest neighbors of each instances are found. Then, based on the evaluation function, for each instance and feature, a weight is calculated, and eventually, the features and instances that are more weighed are retained and the rest are eliminated. IFSB-ReliefF (Instance and Feature Selection Based on ReliefF) algorithm is tested on two datasets and then $\mathrm{C} 4.5$ algorithm classifies the reduced data. Finally, the obtained results from the classification of reduced data sets are compared with the results of some instance and feature selection algorithms that are run separately.

Keywords: data reduction, instance selection, feature selection, ReliefF.

$$
\begin{aligned}
& \text { كرده و ويزگى هاى جديد توليد مى كنند. براى مطالعه بيشتر، } \\
& \text { به [3, 4, }[3,5 \text { مراجعه شود. }
\end{aligned}
$$

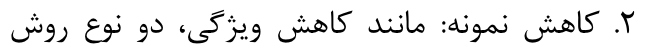

$$
\begin{aligned}
& \text { وجود دارند كه عبارتند از: كاهش نمونه (يا ركورد)، كه } \\
& \text { نمونهبردارى (يا انتخاب نمونه) ناميده مىشود و فشردهسازى } \\
& \text { اطلاعات. در نوع نخست نمونهها با روشهاى تصادفى [6] يا } \\
& \text { روشهاى خاص [7] انتخاب شده و بقيه حذف مىشوند. } \\
& \text { مانند روشهاى استخراج ويزگى، در فشردهسازى اطلاعات } \\
& \text { نمونهها با هم تركيب شده و به شكل محدودتر و فشرده } \\
& \text { تبديل مىشوند. براى مطالعه بيشتر به }[8,9,10,11 \\
& \text { مراجعه شود. }
\end{aligned}
$$

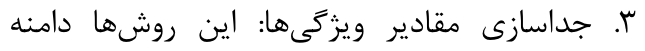

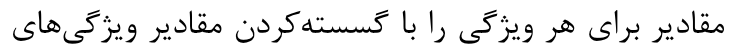

$$
\begin{aligned}
& \text { عددى ييوسته كاهش مي دهند [12] . }
\end{aligned}
$$

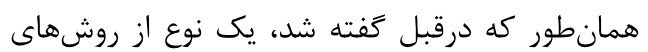

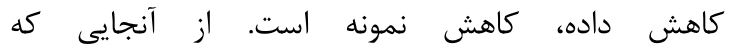

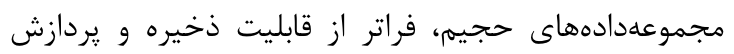

$$
\begin{aligned}
& \text { سامانههاى معمولى هستند [13] ، اين نوع كاهش داده لازم }
\end{aligned}
$$

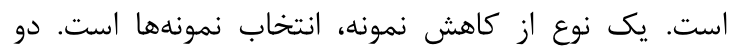

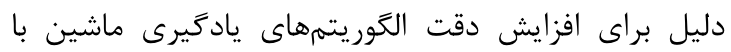

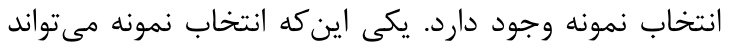

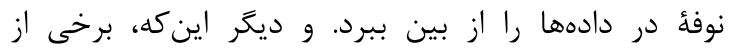

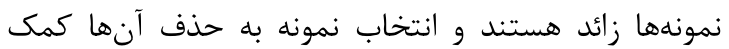

$$
\begin{aligned}
& \text { - } 1 \\
& \text { در سالهاى اخير، بهدليل استفاده از اينترنت و بهخصوص } \\
& \text { شبكههاى اجتماعى، رشد دادهها بسيار سريع بوده است. بله }
\end{aligned}
$$

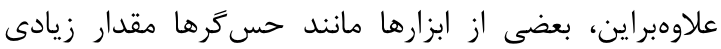

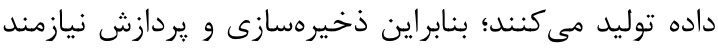

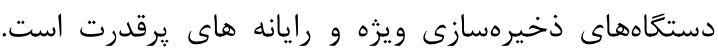

$$
\begin{aligned}
& \text { يكى از جالشهاى ذخيره و زيردازش دادههاى بزرگ، } \\
& \text { فشردهسازى و استخراج اطلاعات مفيد است. بسيارى از } \\
& \text { الخوريتهمها و روشها براى حل اين مشكل اردائه إسته شدهاند. }
\end{aligned}
$$

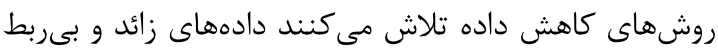

$$
\begin{aligned}
& \text { را حذف كنند تا دقت نتايج را افزايش داده و يا زمان و هزينه } \\
& \text { فرآيندها را كاهش دهند [1] . اين روشها اغلب در مرحله } \\
& \text { ييشيردازش الخوريتمهاى يادگيرى ماشين استفاده }
\end{aligned}
$$

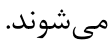

$$
\begin{aligned}
& \text { سه نوع روش كاهش داده مىتواند بر روى دادهها }
\end{aligned}
$$

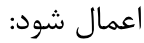

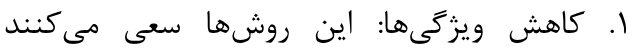

$$
\begin{aligned}
& \text { ويزگىهاى مربوط را ييدا كرده و ويزگى هاى نوفهدار و غير }
\end{aligned}
$$

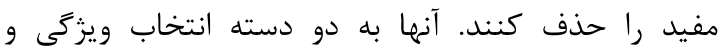

$$
\begin{aligned}
& \text { استخراج ويزگى تقسيم مىشوند. روشهاى انتخاب ويزگى دئ، }
\end{aligned}
$$

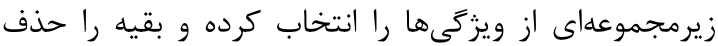

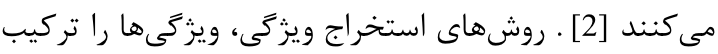

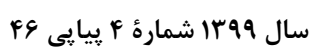


مى كنند [20] . روشهاى فيلتر سريع و بىطرفانه هستند [2]. همجنين روشىهاى فيلتر نسبت به روشهاى بستهبندى در برخورد با مجموعهدادههاى حجيم بلدليل انجام محاسبات

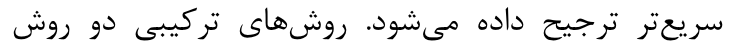
يادشده را تركيب و از مزاياى آنها استفاده مىكنيخ [2].

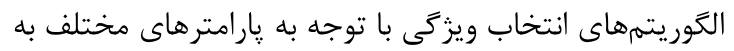

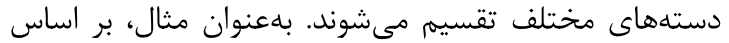

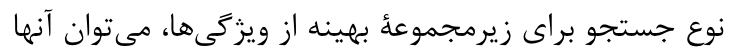
را به سه دسته تقسيم كرد: جستجوى نمايى ل(جستجو براى هر زيرمجموعه ممكن براى يافتن زيرمجموعه مطلوب)،

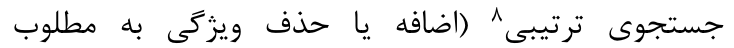
زيرمجموعه در هر مرحله) و جستجوى تصادفى (انتخاب

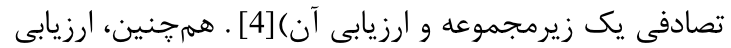

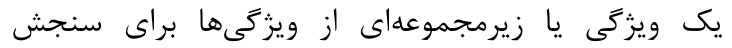

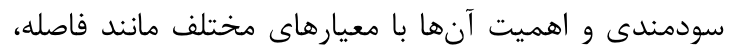

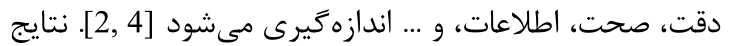
الخوريتمهاى انتخاب ويزگى مى متوانند از يكى الخوريته دادهاوى براى مقايسه دقت مجموعه انتخاب شده و و مادى

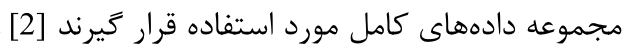
ReliefF

الكوريتم براى محاسبه وزن براى هر ويزگى و رتبهبندى

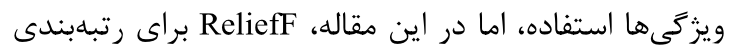
و انتخاب نمونهها و ويزگگىها استفاده مىشود. الكوريتم

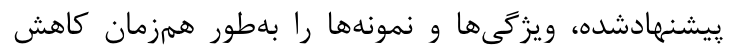

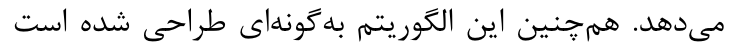

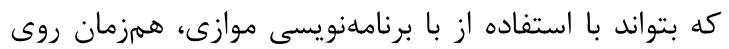

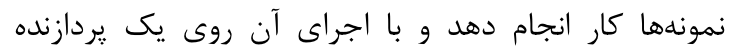
جندهستهاى، زمان اجرا تا حد بسيار زيادى كاهش مى لتهيابد. الخوريتم IFSB-ReliefF (انتخاب نمونه و ويثز بر روى جهار مجموعه داده آزمايش شده است و و

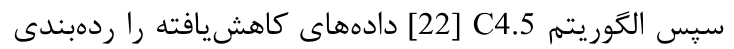

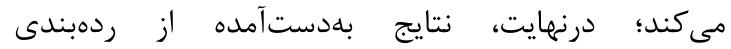

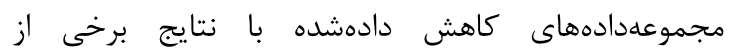
الكوريتمهاى انتخاب نمونه و ويزگى كه بهطور جداكانه اجرا

$$
\text { مىشوند، مقايسه مى شود. }
$$

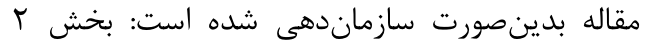

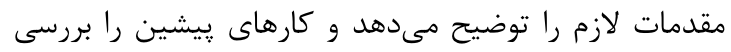

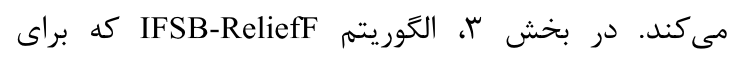

${ }^{7}$ Exponential

${ }^{8}$ Sequential

${ }^{9}$ IFSB-ReliefF: Instance and Feature Selection Based on ReliefF
مى كند. بسيارى از الكوريتمهاى انتخاب نمونه بهدليل كارايى

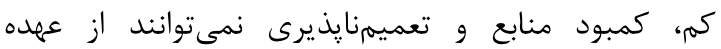

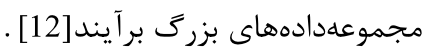

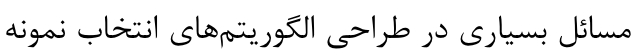

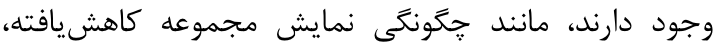
نحوه ايجاد يك زيرمجموعه از نمونها، انتخاب تابع فاصله

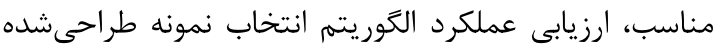

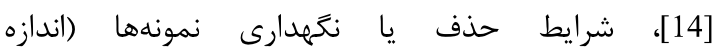
مجموعهدادههاى كاهش داده شده) و ر تعيين نمونههاى بحرانى و نقاط مرزى [15] .

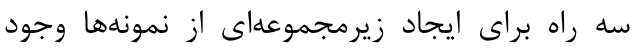

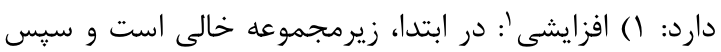

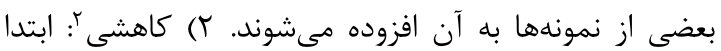

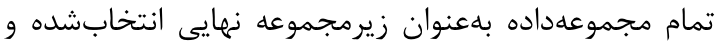

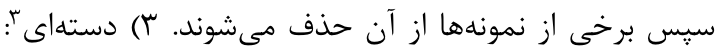

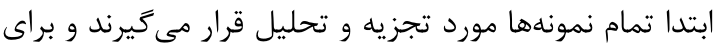

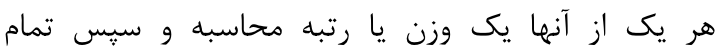

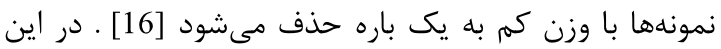
مقاله، از روش دستهاى براى انتخاب نمونهها استفاده مىشود. يكى ديخر از مسائل مهلم، اندازهخيرى شباهت

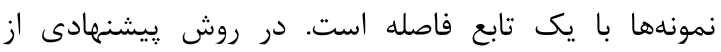

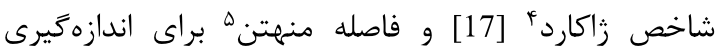
شباهت نمونهها استفاده مىشود. همجنين، تصميمَّيرى درباره تعداد نمونههايى كه بايد حذف شوند يا باقى بمانند،

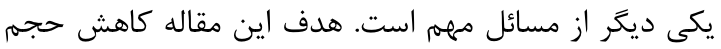
نمونههاى ذخيرهشده در عين حفظ كيفيت مجموعهدادهها

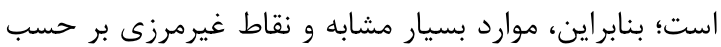

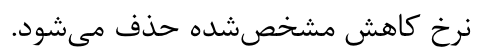

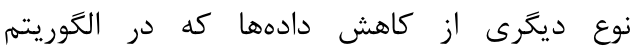
ييشنهادى انجام مىشود، انتخاب ويزگى است. روشى رهاى

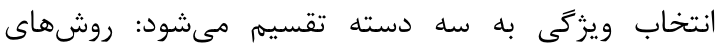

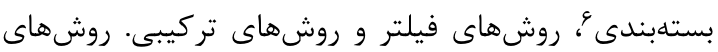

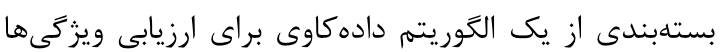

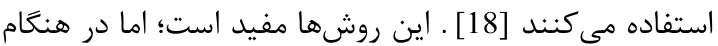

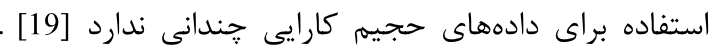
روشهاى فيلتر از الكوريتمهاى دادهاوى استفاده نمى كنند و از طريق يك تابع ارزيابى، ويزگىهاى مربوطه را جستجو إنهاي

\footnotetext{
${ }^{1}$ Incremental

${ }^{2}$ Decremental

${ }^{3}$ Batch

${ }^{4}$ Jaccard index

${ }^{5}$ Manhattan distance

${ }^{6}$ Wrapper
} 
جندردهاى و مجموعهدادهها با مقادير مفقود كار كند [21] . بdمنظور غلبه بر اين مشكلات، الكوريتم Relief اصلاحشده است و الكوريتم جديدى به نام ReliefF ارائه شد [21] • ReliefF مجموعهدادهها با بيش از دو رده داده كار كند. به به جاى مجاى انتخاب يكى از نزديكترين همسايهها، كه در الخوريتم Relief همسايگان يك نمونه انتخابى را ميى يابد؛ علاوهبراين، ReliefF

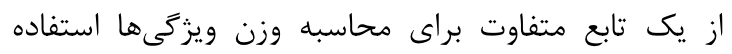
مى كند. اين كار براى مديريت مجموعهدادههاى ناقص انجام

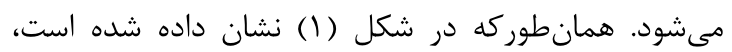

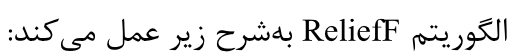

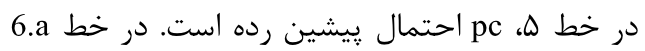
العوريتم يك نمونه تصادفى را انتخاب مى كند. خطوط $6 . b$ تا 6.d انتخابشده به نام Hits و B تا از نزديكترين همسايعان ردههاى ديخر را كه Misses ناميده مىشود، مىيابند. در خط نام

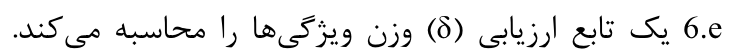

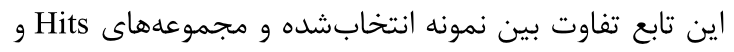

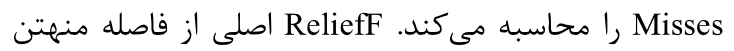
pc/(1 - plass $\left.\left(x_{t}\right)\right)$ (cla

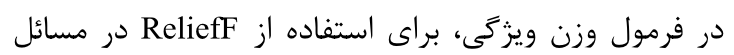

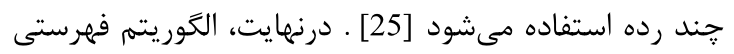
از وزن ويزگى ها را بهدست مى آورد. بر اساس اين فهرست،

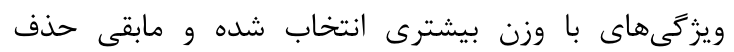

مى شوند [24] - مونس

$1 . / * \mathrm{X}=$ the set of training examples */

2. $/ * \mathrm{~L}=$ the number of random examples to draw */

3. $/ * \mathrm{~B}=$ the number of nearest neighbours to compute*/

4. For each feature $\mathrm{k}\left\{\mathrm{w}_{\mathrm{k}}=0.0\right\}$

5. For each class $\mathrm{c}\{\mathrm{pc}:=$ the fraction of $\mathrm{X}$ belonging to class $\mathrm{c}\}$

dpc:= براى هر كلاس c

6. For $1:=1$ to $L$ do

a) Randomly select an instance $\left(x_{t}, y_{t}\right)$

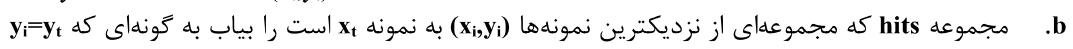
b) Let hits be the set of $B$ examples $\left(x_{i}, y_{i}\right)$ nearest to $x_{t}$ such that $y_{i}=y_{t}$

c) For each class $c \neq y_{t}$
انتخاب ويثزى و نمونه از ReliefF استفاده مى كند، ارائه

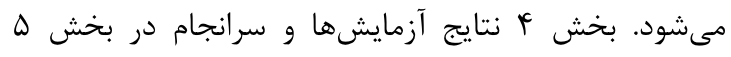
خلاصه و نتيجه كار ارائه مىشود. بخى نائ.

r در اين بخش، ابتدا، الكوريتهم ReliefF توضيح داده شده است. برخى از الكوريتمهاى معرفىشده هم هم نمونه و هم

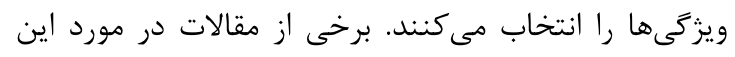
نوع الكوريتمها در اين بخش مورد بررسى قراب مرار كرفته است.

ReliefF $-r-1$

يك راه براى كاهش حجم دادها انتخاب ويزگى [2] است.

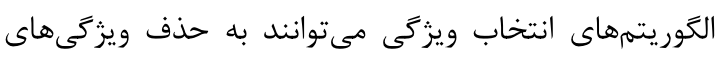

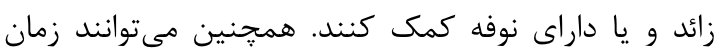

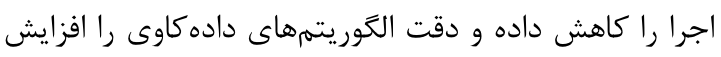

دهند. إز [23 Relief

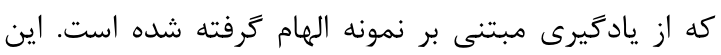

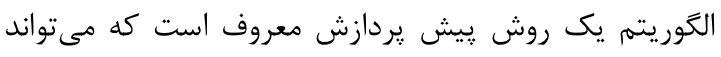

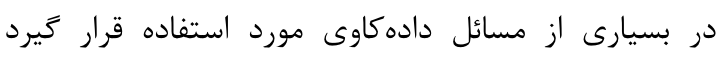

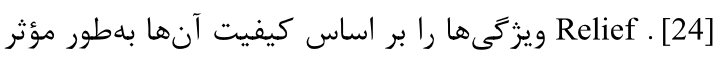

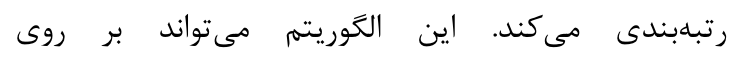

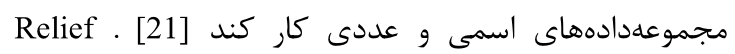

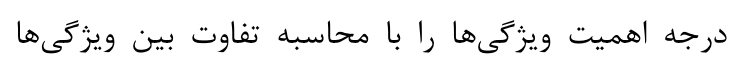

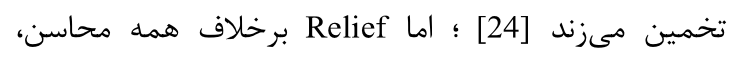

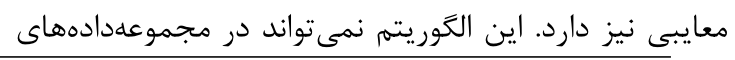

\section{Algorithm ReliefF (input:X, L, B)}

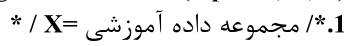

2." تعداد نمونههايى كه بايد بلهور تصادفى انتخاب شوند=L/L

3." تعداد نزديكترين همسايههايى كه بايد محاسبه شوند=/ /

$$
\left\{w_{k}=0.0\right\}: \text { k } 4 .
$$

6. $\left(x_{t}, y_{t}\right)$ a

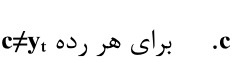

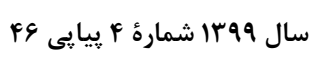


ل Let misses be the set of B examples (xj,yj) Nearest to xt such that yj=c

d) End for

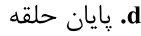

e) For each feature $k$

$$
\text { k e براى هر ويثزى }
$$

$w_{k}=w_{k}-\frac{1}{L B} \sum_{(x i, y i) \in H i t} \delta\left(x_{t, k}, x_{i, k}\right)+\sum_{c \neq y_{t}} \frac{p c}{\left(1-p\left(\operatorname{class}\left(x_{t}\right)\right)\right) L B} \sum_{(x i, y i)} \delta\left(x_{t, k}, x_{j, k}\right)$

f) End for

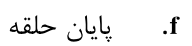

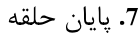

7. End for

8. Return the set of weights (W)

1. مجموعه مقادير وزنها (W) را بهعنوان خروجى بركردان.

9. End Relief

ReliefF بايان

ReliefF شكل -1): شبه كد الكَوريتم

(Figure-1): Pseudo code of ReliefF

اطلاعات براى انتخاب نمونهها و ويزگىها و استفاده از آنها در يك سامانه فيلترينگ تطبيقى' معرفى شده است. دليل

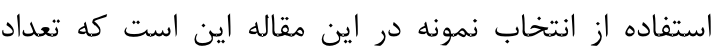

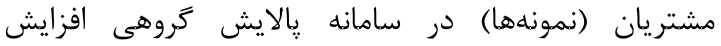

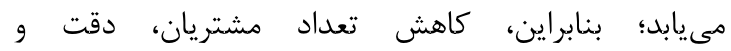
مقياس يذيرى سامانه را افزايش مى دهد. همجنين بانين با توجه به نوع دادههاى خاصى مسأله، از آنجايى كه شئ شناسايى

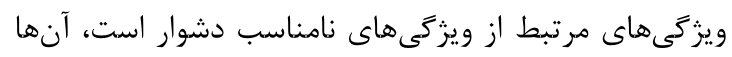

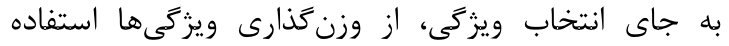

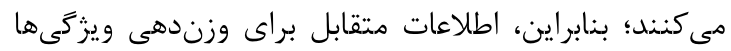
استفاده مىشود. براى انتخاب نمونه، ضريب همبستيتى هرات هر

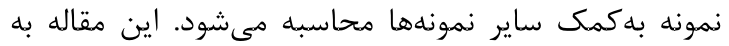

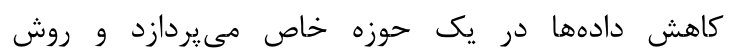
استفادهده قابل تعميم نيست. نتايج مقاله نيز فقط بر روادي

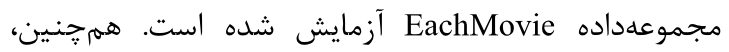

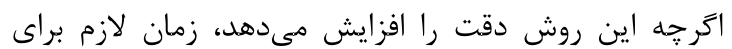

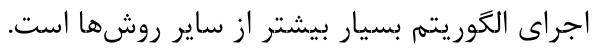

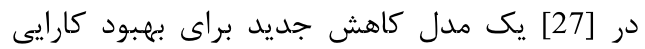

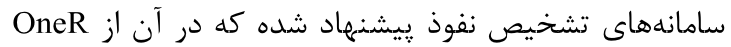

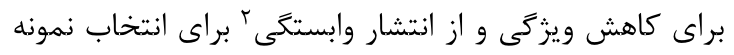

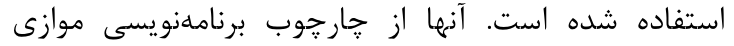

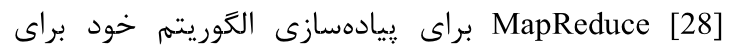
افزايش سرعت كاهش دادهها استفاده كردند. براى آزمايش

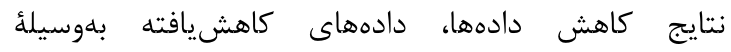
الكوريتمهاى KNN و SVM ردهبندى شدند. اين مقاله بر

${ }^{1}$ Collaborative filtering system

${ }^{2}$ Affinity propagation

\section{r-r- انتخاب همزمان ويزگى ها و زمونهها}

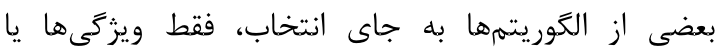
نمونهها مى توانند هم ويزَّى ها و همم نمونهها را انتخاب كنيند. اين انتخاب مىتواند در يك يا جند مرحله انجام شود. اكر

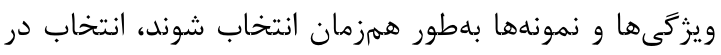
يك مرحله است؛ در غير اين صورت، در خند مرحله خواهد بود. بهعنوان مثال، در [1] يك الكوريتهم تكاملى براى انتخاب

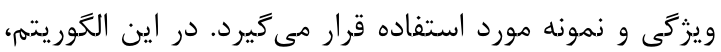
هر كروموزوم داراى n+ m زن است (اكر مجموعهداده داراى

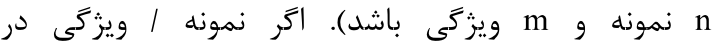

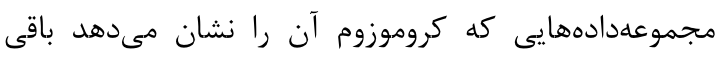
بماند، مقدار زن برابر با يك است، و اكر از مجان مجموعهداده

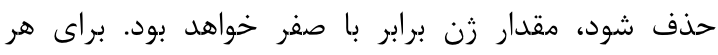

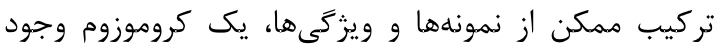
دارد. يك ردهبند براى ارزيابى كروموزومها استفاده مىشوداد

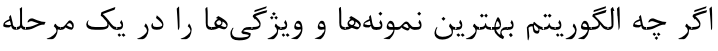
و با دقت زيادى انتخاب مى كند، بهدليل استفاده از يكى ردهبند براى ارزيابى هر كروموزوم، براى مجموعهدادههاى بزرى، اين روش بسيار زمانبر يا غير قابل استفاده خواهد

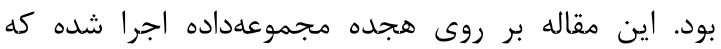
اگر جه ادعا شده شش عدد از آنها در مقياس بزرى هستند؛

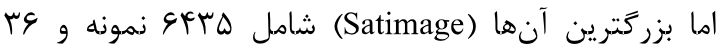
ويزگى است كه از مجموعهدادهاى استفادهشده در اين مقاله بسيار كوجكتر است.

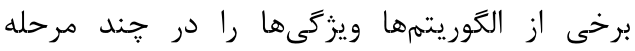
انتخاب مىكنند. در [26] يكى راهكار تئورى مبتنى بر 
يك روش انتخاب ويزگى و نمونه بهطور همزمان براى

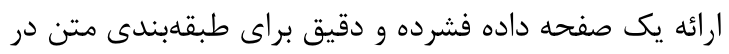

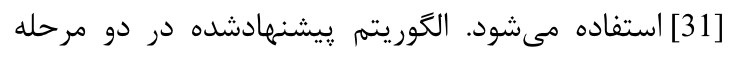

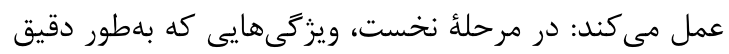

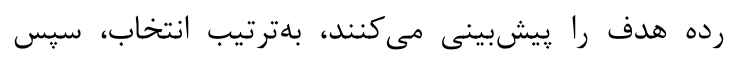

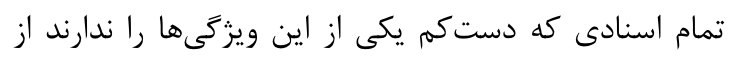

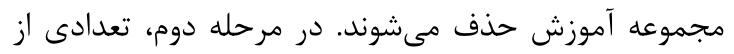

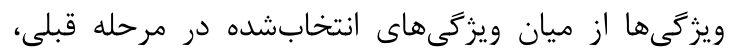

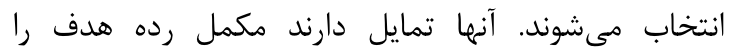

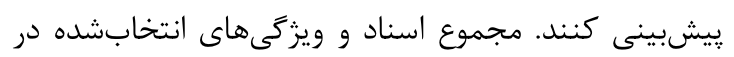

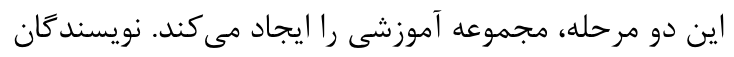

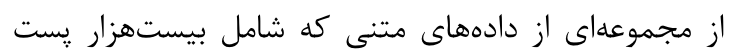

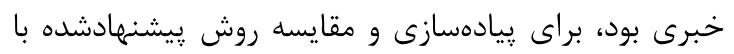
روشهاى ديكر استفاده مى كنيند.

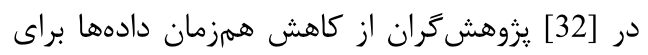

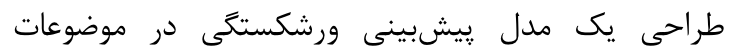

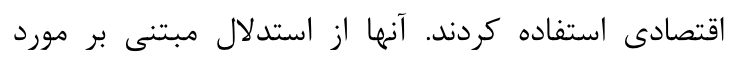

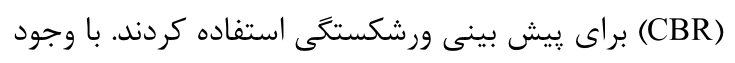

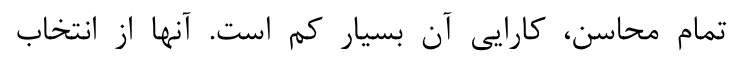

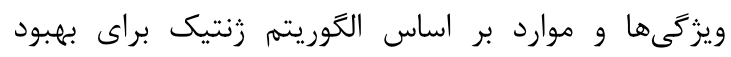

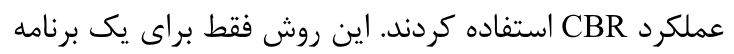

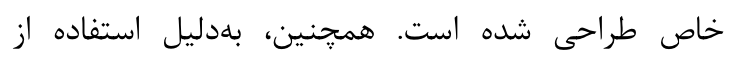

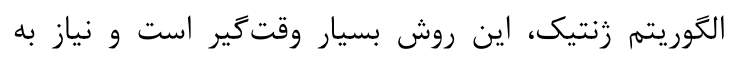

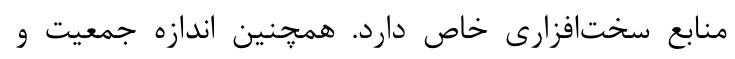

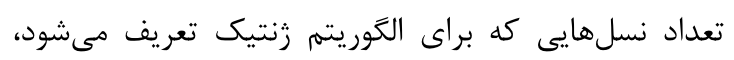

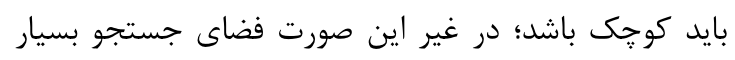

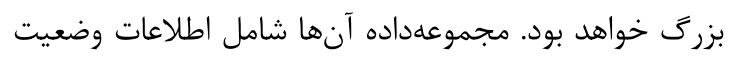

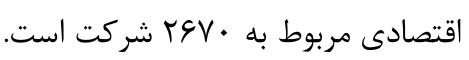

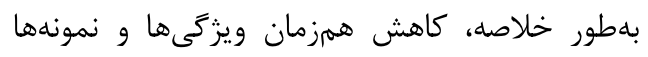

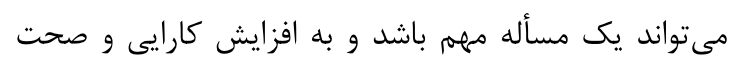

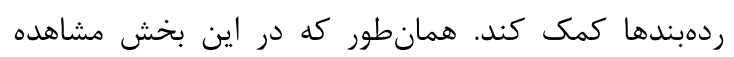

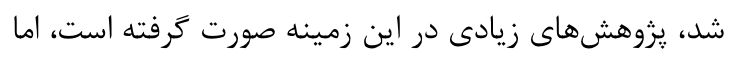

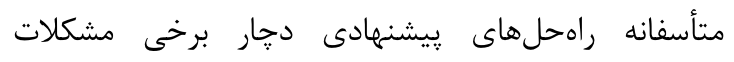

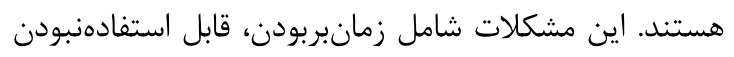

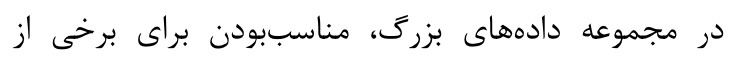

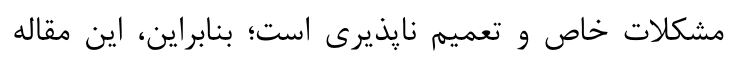

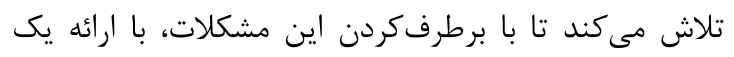

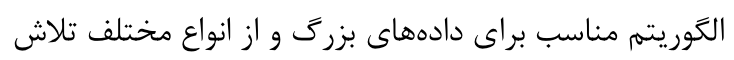

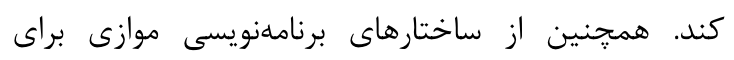

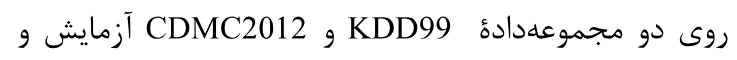
اجرا شد. نويسندكان ادعا كردند كه سرعت تشخيص حمله

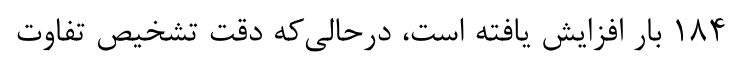
معنى دارى ندارد. يك روش براى ايجاد يك سامانه تشخيص خودكار

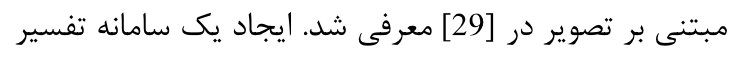

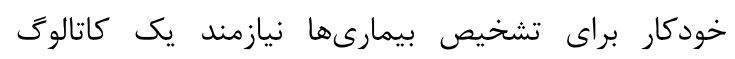

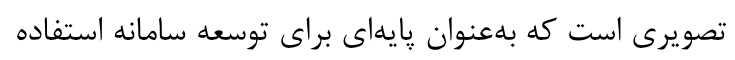

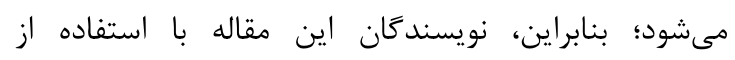

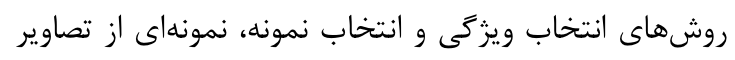

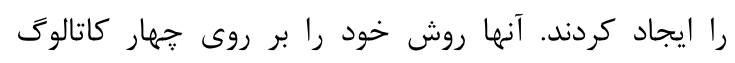

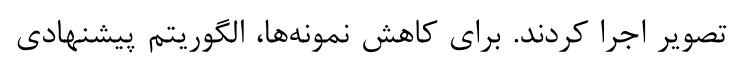

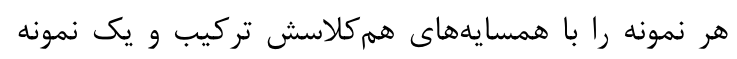

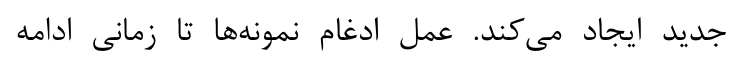

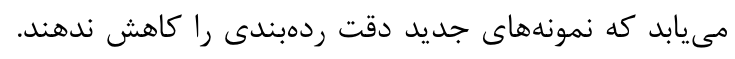

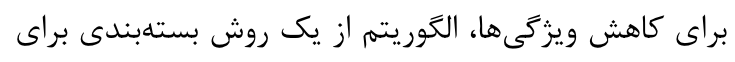

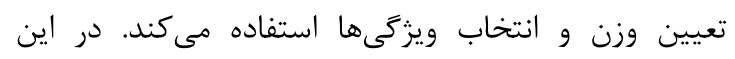

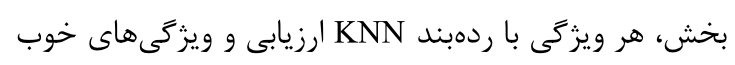

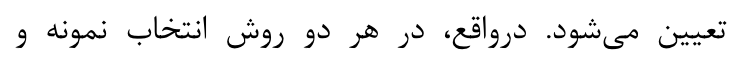

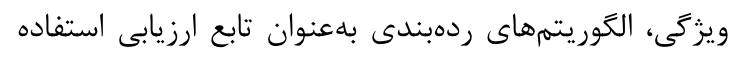

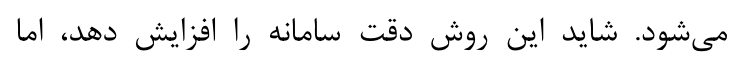

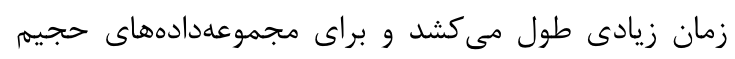
قابل استفاده نيست.

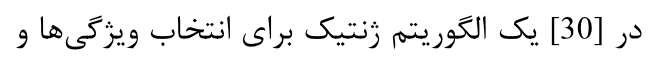

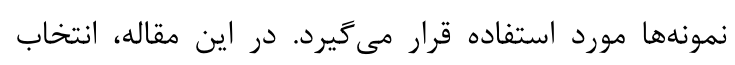

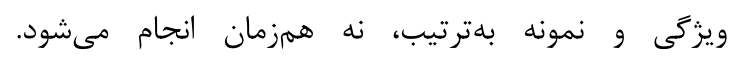

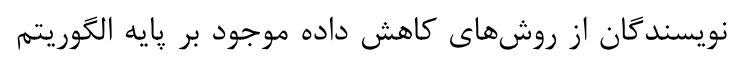

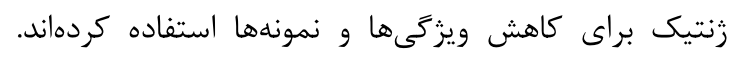

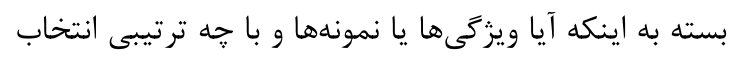

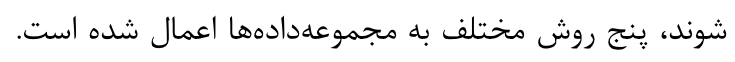

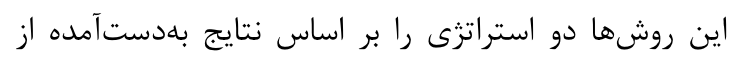

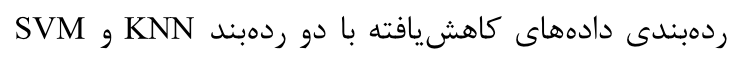

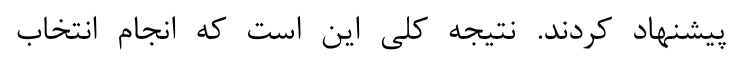

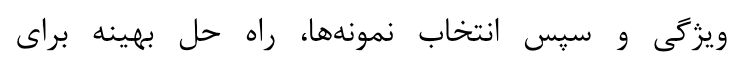

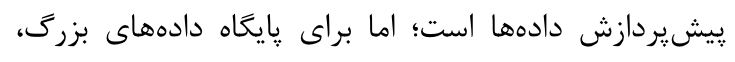

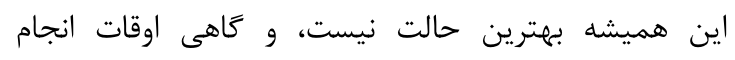

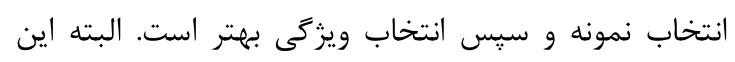

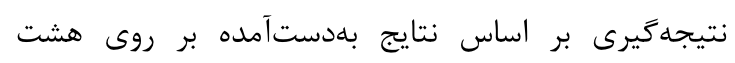

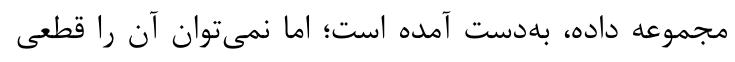

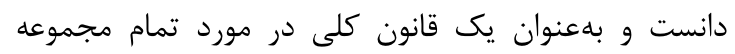
دادها اعمال كرد. 


$$
\begin{aligned}
& \text { ويزگى ها وزنى اختصاص مىدهد. در اين الكوريتم، يك نمونه } \\
& \text { تصادفى در هر تكرار انتخاب و تفاوت آن با مجموعه Hit و }
\end{aligned}
$$

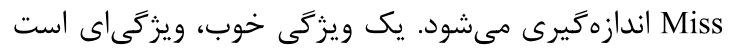

$$
\begin{aligned}
& \text { كه بيشتر شبيه به نزديكترين نمونه از همان رده است و و }
\end{aligned}
$$

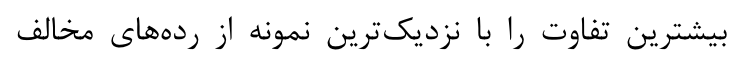

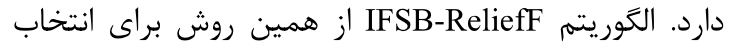

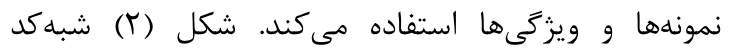

$$
\begin{aligned}
& \text { IFSB-ReliefF }
\end{aligned}
$$

1. $/ * \mathrm{X}=$ the set of training examples */

2. $/ * \mathrm{~B}=$ the number of nearest neighbors to compute*/

3. $/ * \mathrm{~L}=$ Number of instances. $* /$

4. For $t:=1$ to $L$ do (This loop can run in parallel)

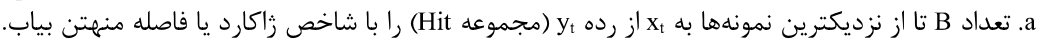

a) Find $B$ nearest instances to $x_{t}$ from class $y_{t}$ (Hit set) by Jaccard index or Manhattan distance

b) For each class $\mathrm{c} \neq \mathrm{y}_{\mathrm{t}}$

$$
c \neq y_{t} 00 \text { ر براى هر b }
$$

تعداد B تا از نزديكترين نمونهها به xt از هر رده c را با شاخص زاكارد يا فاصله منهتن بياب و به مجموعه Miss اضافه كن. Find B nearest instances to xt from class c and add to Miss set by Jaccard index or Manhattan distance c. (خايان حلقه (خط

c) End for (line 4.b)

d) Calculate the weight of each instance $\mathrm{x}_{\mathrm{t}}$ and put it in array $\mathrm{W}$ :

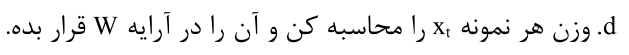

$$
\begin{aligned}
& \mathbf{w}_{\mathbf{t}}=\sum_{\mathbf{c} \neq \mathbf{y}_{\mathbf{t}}} \frac{1}{\mathrm{LB}} \sum_{(\mathrm{x}, \mathrm{y}, \mathrm{j}) \in \mathrm{Miss}} \delta\left(\mathbf{x}_{\mathrm{t}}, \mathrm{x}_{\mathrm{j}}\right)-\frac{1}{\mathrm{LB}} \sum_{(\mathrm{xi}, \mathrm{y} \mathrm{i}) \in \mathrm{Hit}} \delta\left(\mathrm{x}_{\mathrm{t}}, \mathrm{x}_{\mathrm{i}}\right) \\
& \text { e. براى هر ويزگى k از نمونه Xt وزن را محاسبه كن و آن را در آرايه WFI قرار بده. }
\end{aligned}
$$

e) For each feature $\mathrm{k}$ of $\mathrm{x}_{\mathrm{t}}$ calculate the weight and put it in array WF:

$$
w f_{t k}=\sum_{c \neq y_{t}} \frac{p c}{\left(1-p\left(\operatorname{class}\left(x_{t}\right)\right)\right) L B} \sum_{(\mathrm{xj}, y \mathrm{j}) \in \mathrm{Miss}} \delta\left(x_{t, k}, x_{j, k}\right)-\frac{1}{L B} \sum_{(x i, y i) \in H i t} \delta\left(x_{t, k}, x_{i, k}\right)
$$

f) End for (line 4.e)

5. End for (line 4)

$$
\text { f.e بايان حلقه (خط f.e. }
$$

5.

$$
\text { 6. بهازاى هر ويزگى k، ميانگين وزن تمام مقادير موجود در WFI را محاسبه كن و يك وزن براى هر ويزگى بهدست آور و در WF قرار بده. }
$$

6. Calculate the average of all $\mathrm{Wf}_{\mathrm{tk}}$ and get a weight for each feature Wf.

7. Sort the weight array $\mathrm{W}$ and Wf.

$$
\text { 7. آرايه وزن WF و W W ا مرتب كن. }
$$

8. بر اساس آرايه مرتب شده W، از هر كلاس با توجه به pc (احتمال ييشين) آن نمونههايى كه وزن بيشترى دارند را انتخاب كرده و در آرايه Out قرار

8. Based on the sorted array W, select instances that have more weight from each class according to the proportion to be selected and put in the output array.

$$
\text { 9. بر اساس آرايه WF، ويزّى هاى با وزن بيشتر را از آرايه Out انتخاب كرده و در آرايه خروجى قرار بده. }
$$

9. In the output array, based on WF array, keep the features with more weight and remove the rest.

$$
10
$$

1.. End Proposed Algorithm.

IFSB-ReliefF شكل - ( الكور):

(Figure-2): Pseudo code of IFSB-ReliefF
در خط أ، يك حلقه تكرار به تعداد همه نمونهها
همانطوركه در شكل نشان داده شده، IFSB

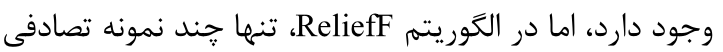
ReliefF 
$\mathbf{J}(\mathbf{X}, \mathbf{Y})=\frac{|\mathbf{X} \cap \mathbf{Y}|}{|\mathbf{X} \cup \mathbf{Y}|}$

برخى از ويزگكىهاى مجموعلدادهها مقادير مفقود

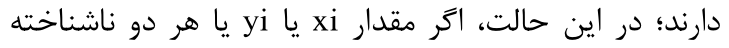

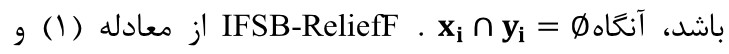

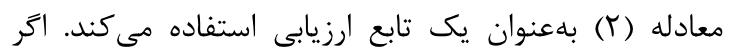

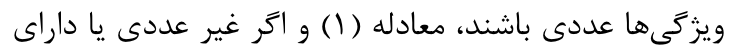
مقادير مفقود باشند، معادله (r) استفاده مى شود.

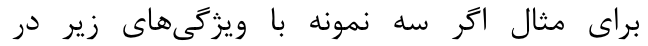

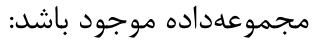

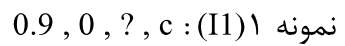

$$
\begin{aligned}
& \text { نمونه r (I2): } 0.15,0.5, \text { a , b } 0.15
\end{aligned}
$$

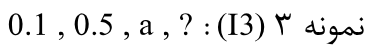

براى محاسبه شاخص زاكارد براى نمونه او با و ونمونه

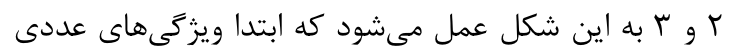

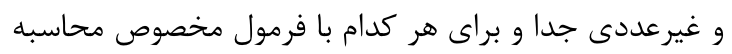

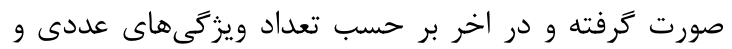
غيرعددى، ميانكين كرفته مى مشود. $\mathrm{J}(\mathrm{I} 1, \mathrm{I} 2)_{\text {num }}=\frac{\min (0.9,0.15)+\min (0,0.5)}{\max (0.9,0.15)+\max (0,0.5)}$

$$
=\frac{0.15+0}{0.9+0.5}=0.107
$$

$\mathrm{J}(\mathrm{I} 1, \mathrm{I} 2)_{s t r}=\frac{|\varnothing|}{|(a, b, c, ?)|}=0$

$\mathrm{J}(\mathrm{I} 1, \mathrm{I} 2)=\frac{0.107+0}{2}=0.053$

$\mathrm{J}(\mathrm{I} 2, \mathrm{I} 3)_{\mathrm{num}}=\frac{\min (0.15,0.1)+\min (0.5,0.5)}{\max (0.15,0.1)+\max (0.5,0.5)}$

$\mathrm{J}(\mathrm{I} 2, \mathrm{I} 3)_{\text {str }}=\frac{|(a)|}{|(a, b, ?)|}=0.333$

$$
=\frac{0.1+0.5}{0.15+0.5}=0.92
$$

$\mathrm{J}(\mathrm{I} 2, \mathrm{I} 3)=\frac{0.92+0.333}{2}=0.628$

با توجه به مثال، مشاهده مىشود كه از نظر شاخص

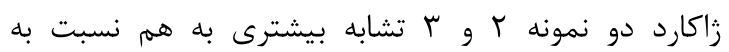
نمونههاى او دار دارند.

براى هر نمونه، الكوريتم نمونههايى را براى مجموعه

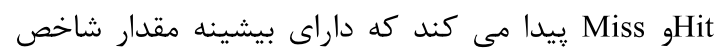

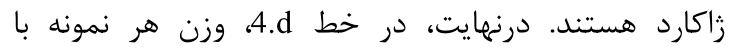

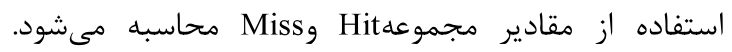

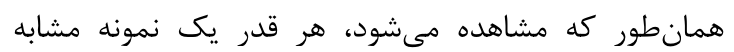

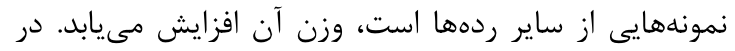

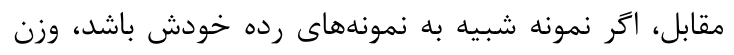

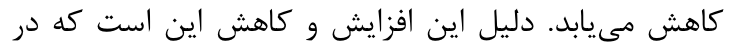

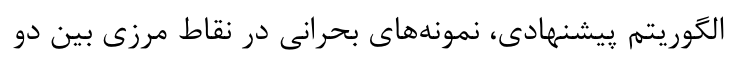

انتخاب مىشود. اگر جه اين كار وقت گير خواهد بود، جون دستورهاى داخل حلقه بهطور مستقل براى إنى يك نمونه اجرا

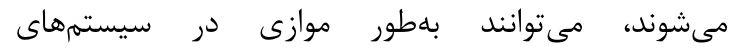

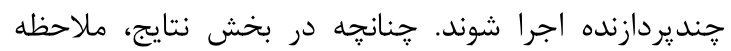

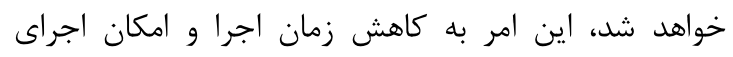

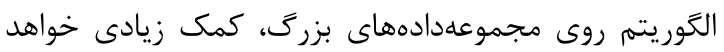
كرد. مانند ReliefF در خطوط

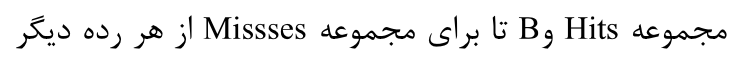

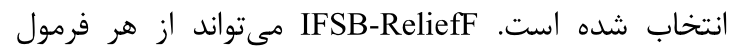

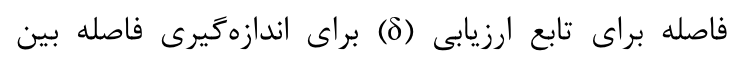

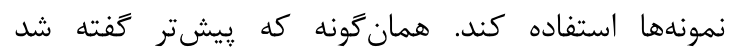
ReliefF

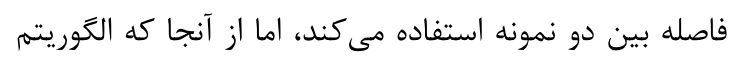
ReliefF

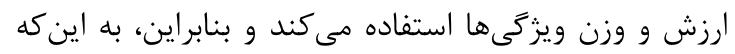

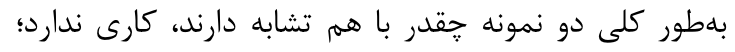

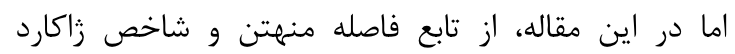

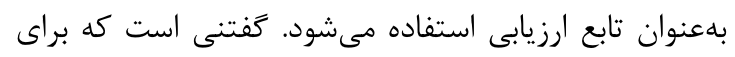

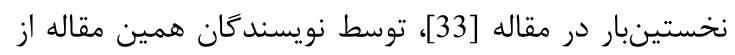

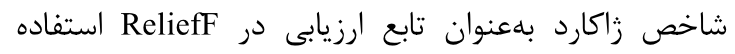

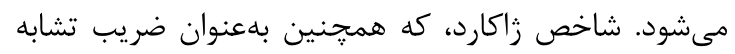

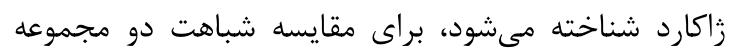

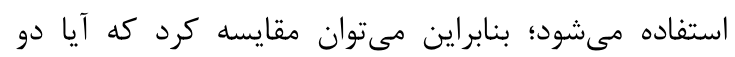

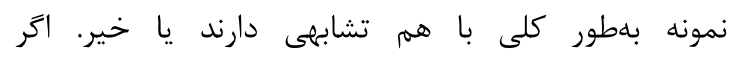

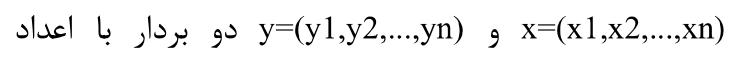

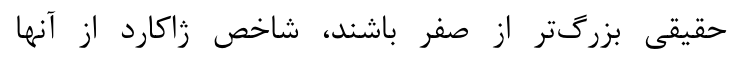
$\mathbf{J}(\mathbf{X}, \mathbf{Y})=\frac{\sum_{\mathbf{i}} \min \left(\mathbf{x}_{\mathbf{i}}, \mathbf{y}_{\mathbf{i}}\right)}{\sum_{\mathbf{i}} \max \left(\mathbf{x}_{\mathbf{i}}, \mathbf{y}_{\mathrm{i}}\right)}$

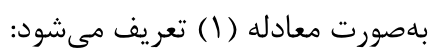

از آنجا كه اين فرمول براى اعداد حقيقى بيشتر از

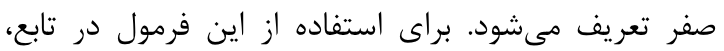

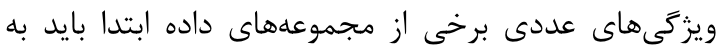

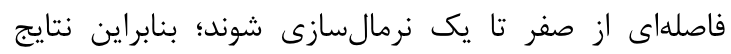

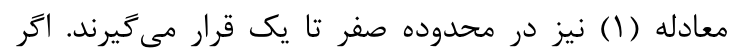

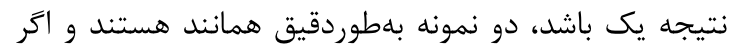

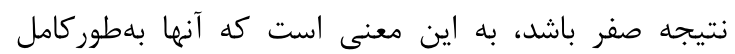
متفاوت هستند و بين آنها هيج شباهتى وجود ندارد.

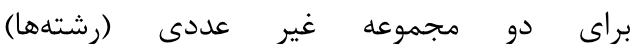

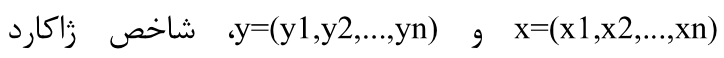
بلهصورت معادله (r) تعريف مىشود: 
اجرا شود؛ سيس نتايج ردهبندى دادههاى كاهشيافته با

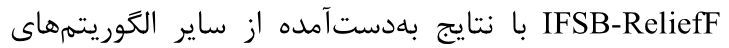
كاهش مقايسه مىشود. براى آزمايش نتايج الكوريتم، جندين

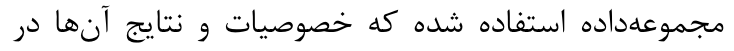
بخش بعدى توضيح داده خواهد شد.

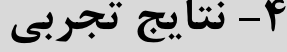

در اين بخش، نتايج ردهبندى دادههاى انتخابشده بلوسيلة IFSB-ReliefF

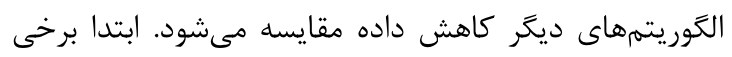

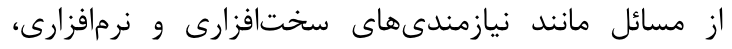

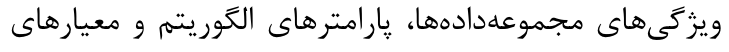

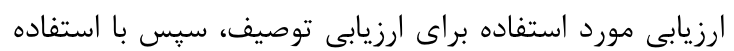
از الكَوريتهم ردهبندى براى كاهش دادهها، عملكرد الكَوريتهها در جهار مجموعه داده ارزيابى مىشود؛ درنهايت، نتايج

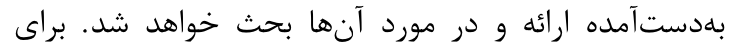

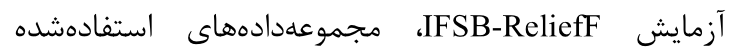
شامل انواع دادهاى مختلف (عددى و غيرعددى) و مقادير

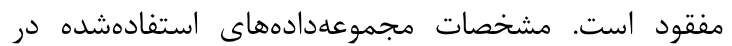

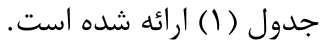

(جدول - ()): مشخصات مجموعههاى داده

(Table-1): 1 Datasets characteristics

\begin{tabular}{|c|c|c|c|c|c|}
\hline مقادري & نوع ويزَّى & كلاس & تعداد & تعدونه & مجموعه داده \\
\hline خير & عددى & 10 & 784 & 50,000 & $\begin{array}{l}\text { MNIST (test } \\
\text { part) }^{1}\end{array}$ \\
\hline خير & عددى & 3 & 4 & 625 & $\begin{array}{c}\text { Balance- } \\
\text { Scale2 }\end{array}$ \\
\hline بله & غير عددى و & 2 & 41 & 30,000 & Census $^{3}$ \\
\hline خير & غير عددى و & 2 & 20 & 1000 & $\begin{array}{l}\text { German } \\
\text { credit4 }\end{array}$ \\
\hline
\end{tabular}

مشخصات سختافزارى و نرمافزارى سامانه عبارتند

Intel® Xeon® CPU E5-2620v4@ • •

\section{$2.10 \mathrm{GHz}$ (2 processors)}

${ }^{1}$ http://www.cs.ubc.ca/labs/beta/Projects/autoweka/datasets/ mnist.zip

${ }^{2} \mathrm{http}: / /$ archive.ics.uci.edu/ml/datasets/balance+scale

${ }^{3} \mathrm{https}: / /$ archive.ics.uci.edu/ml/datasets/Census-

Income+\%28KDD\%29

${ }^{4} \mathrm{https}: / /$ archive.ics.uci.edu/ml/datasets/statlog+(german + cre dit+data)
رده براى تشخيص مهممتر هستند. درحقيقت، نمونهايى كه

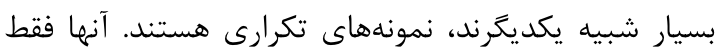

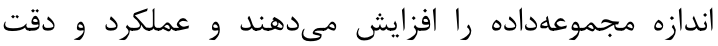
طبقهبندى را بهبود نمى دهند.

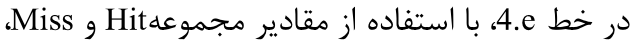
وزن هر ويزگى نيز محاسبه مىشود. كفتنى است كه pc و p(class $\left.\left(x_{t}\right)\right)$ ) نمونههاى هر رده به كل نمونهها، است. اين احتمال بايد قبل از شروع الكوريتم محاسبه شود. يس از يايان حلقه اصلى برنامه در خط ه، دو آرايه از وزن وجود دارد، يكى براى نمونه

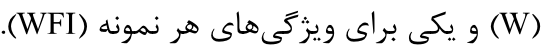

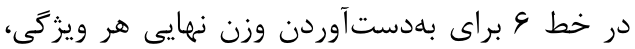

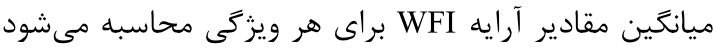

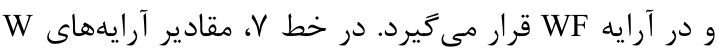

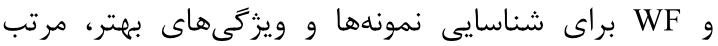
مىشوند.

در خط ^، بر اساس pc، نمونههايى با وزن بالاتر

انتخاب مىشوند. يكى از اصلاحاتى كه در IFSB-ReliefF انجام شده، درنظرگرفتن نسبت نمونههاى انتخابشده از هر رده نسبت به همه نمونههاى آن رده است. دليل اين امر اين

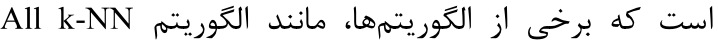
[34]، احتمال ييشين هر رده را در نظر نخرفته و انتخاب إنهاب كوركورانهاى انجام مىدهند. اين ممكن است باعث عدم تعادل بين نسبت ردهها شود. همجنين در برخى موارد، كهن إنه در آن يك رده فقط جند نمونه دارد، ممكن است، تمام نمونههاى آن حذف شده و هيج ردى از اين رده باقى نماند؛ بنابراين، اين بهبود در IFSB-ReliefF به حفظ وضعيت اوليه مجموعهدادهها كمك مى كند. البته، روش محاسبه را معى موران براى نغگهدارى تعداد بيشترى از نمونههاى رده اقليت و حل

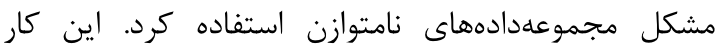
مىتواند با محاسبه احتمال يِيشين هر رده و با انتخاب نمونههايى با وزن بيشترى از هر رده انجام شود. تعداد

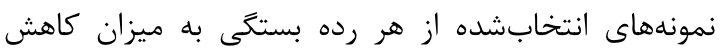
دارد. درنهايت، در خط 9، فيلتركردن ستونها (ويزَكىها) در

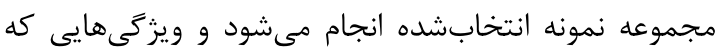
وزن بيشترى دارند، حفظ شده و بقيه حذف مىشوند. خروجى الكوريتم IFSB-ReliefF يك مجموعهداده است كه هم از نظر تعداد سطرها و هم از نظر تعداد ستونها كاهش يافته است. بلمنظور بررسى موفقيت الگوريتم كاهش داده، بايد الكوريتم ردهبندى بر روى دادههاى كاهشيافته 
ردهبندى مىشود. اين الكوريتم يك درخت تصميم را توليد

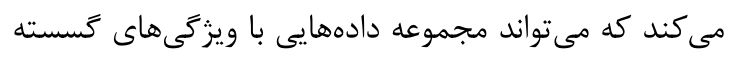

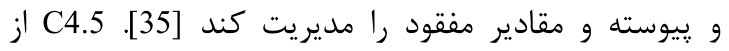
آنترويى اطلاعات براى ايجاد درخت استفاده مى كند. C4.5،

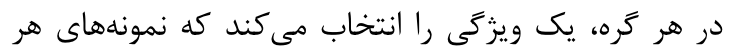
رده را بهطور مؤثرتر جدا مى كند. در تمام آزمايشها (به جرئ

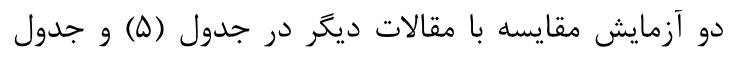

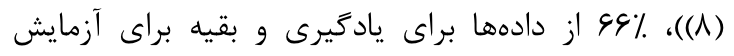

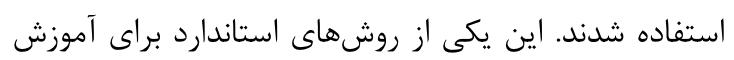

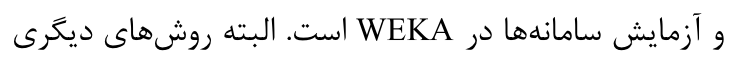

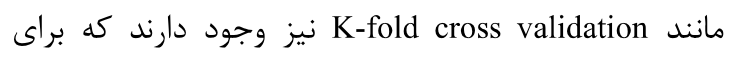

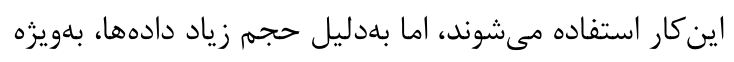

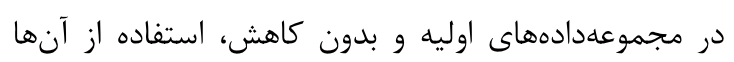

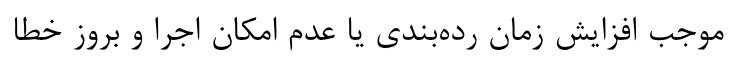

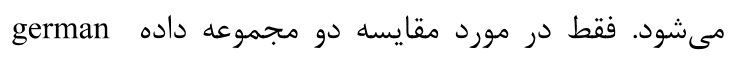

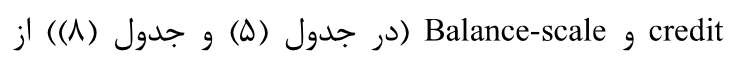
روش 10-fold cross validation استفاده شده است. براى ارزيابى نتايج، معيارهاى كارايى زير بهكار

رفتهاند:

• نرخ كاهش: اين معيار نرخ كاهشداده را مشخص كرده

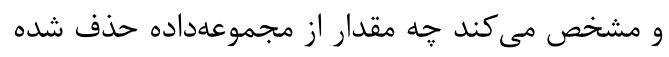

$$
\text { است. و با فرمول زير بهدست مى آيد [36, }
$$

نرخ كاهش= اندازه مجموعه كاهشيافتها اندازئ لبده مجموعه

در اين مقاله اين معيار با واحد درصد نشان داده

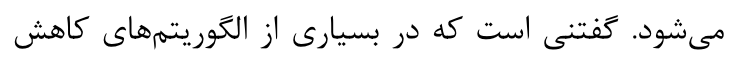

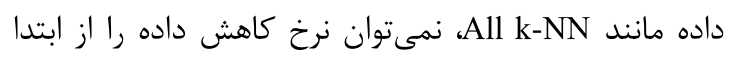

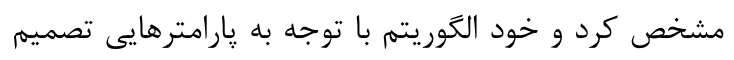
مى $)^{~}$

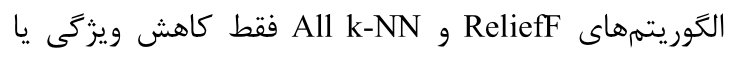
كاهش نمونه را انجام مى دهند، حتى اتر نرخ كاهش آنها IFSB-ReliefF

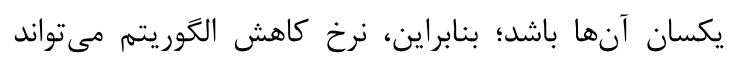

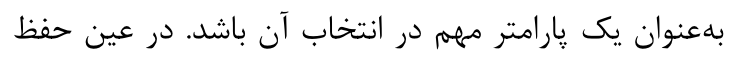

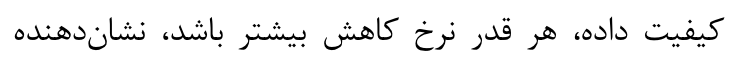
برترى الكوريتهم خواهد بود.

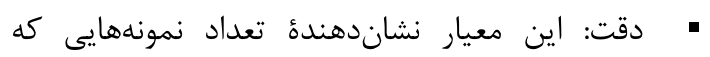

بلهور صحيح ردمبندى شدهاند نسبت به كل نمونهها

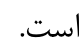

RAM •

• سيستم عامل: Win 764 bit

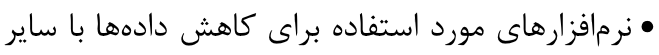
الكوريتمهاى كاهش و همرجنين ردهبندى دادهاى دادها:

WEKA 3.8 Rapid Miner

• نرمافزار مورد استفاده براى اجراى IFSB ReliefF

.Matlab r2013

براى ارزيابى نتايج IFSB-ReliefF، آنها با نتايج

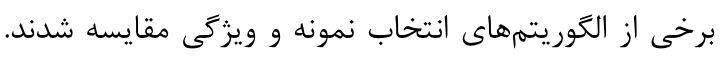

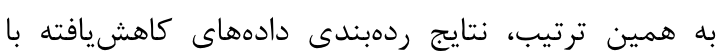
نتايج مجموعه دادههاى اصلى مقايسه شد. ردئ

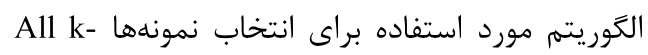

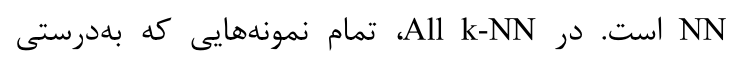

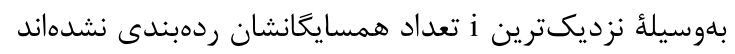

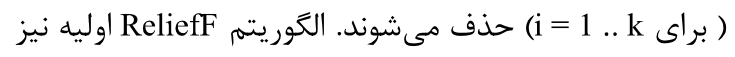

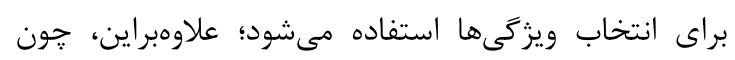

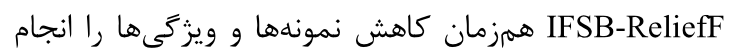

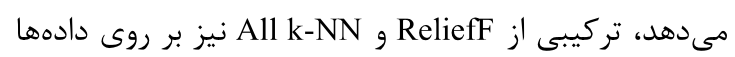

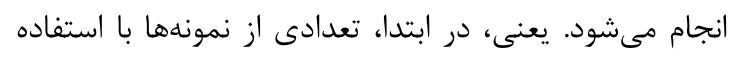

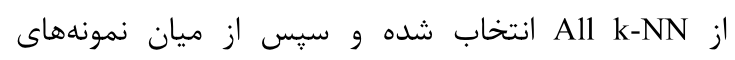

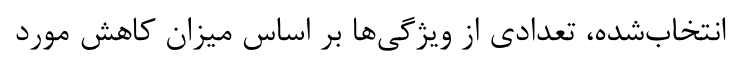
نظر انتخاب و بقيه حذف مىشوند.

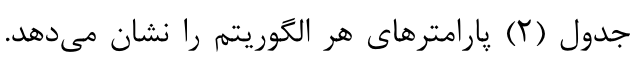

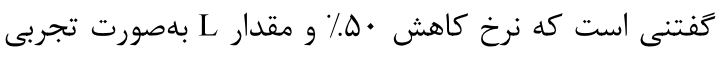

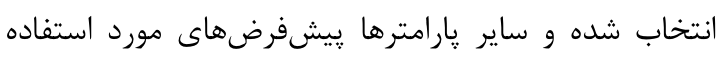

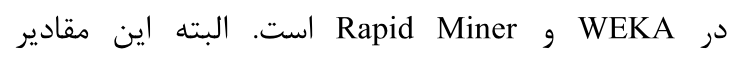

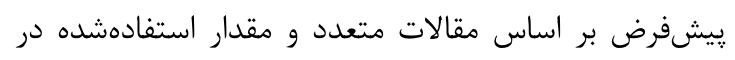

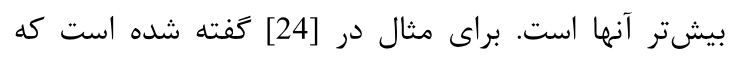

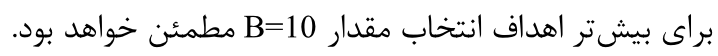

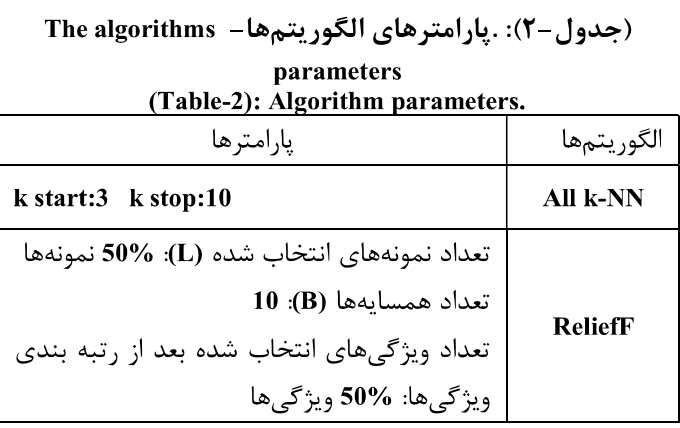

براى ارزيابى كيفيت نتايج حاصل از IFSB-ReliefF،

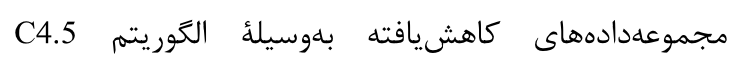


بلهصورت موازى 8671 ثانيه است، در صورتى كه اكر الكَوريتم

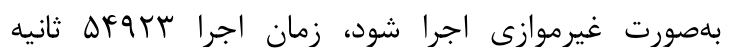
خواهد بود. همجنين در مورد تابع ارزيابى مورد استفاده در IFSB-ReliefF كاهش VDI/، از نظر ميزان دقت ردهبندى و و بلهورتقريبى مشابه هم هستند و فقط در نرخ كاهش

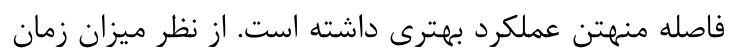
مصرفشده نيز بهطورتقريبى مشابهاند، و فقط روش زاكارد، كمى زمان بيشترى صرف مى كند.

در جدول (F) نتايج مربوط به مجموعلداده

ارائه شده است. در اين جدول نيز بهترين دقت مربوط

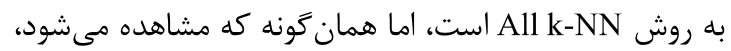
اكرجه زمان كمى براى اجرا صرف شده، نرخ كاهش تنها

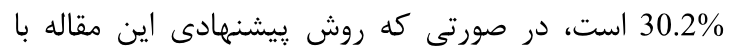
فاصله منهتن و نرخ كاهش

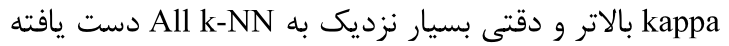

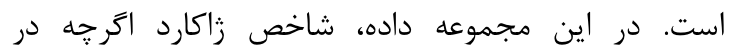
شاخصهاى ردهبندى عملكرد ضعيفترى از فاصله منتهن

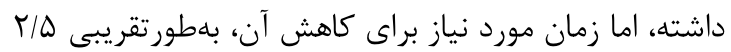

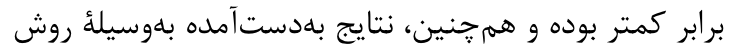
IFSB-ReliefF مقايسه شده است. براى مقايسه بين روشها از ردات ردبند

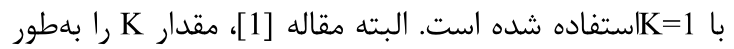

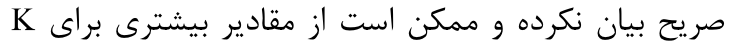

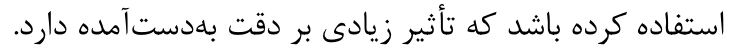
براى مثال در روش IFSB-ReliefF اكر مقدار دقت بلدستآمده براى نرخ تابع ارزيابى فاصله منهتن (مورد

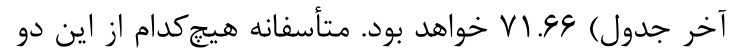
مقاله سختافزار مورد استفاده خود را بيان نكردند تا زمان آنان

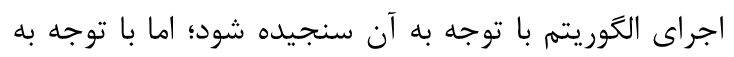
اينكه هر دو الكوريتم [1] و [30] از الكوريتم رثنتيك و و ردهبندها براى بررسى و كاهش نمونهها و ويزگكىها استفاده

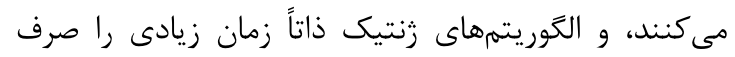
ارزيابى يك جواب و محاسبه ميزان بهينتى آن مئى كنند،

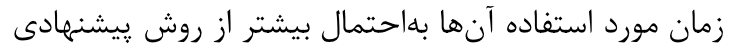

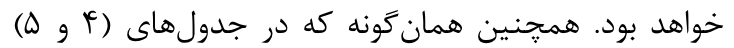

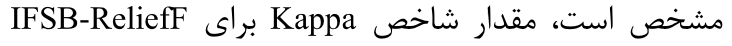
بيشتر از ساير روشها است. اين شاخص نشان نشاندهنده تصادفىبودن يا نبودن نتايج است و هر جقدر به به يك نزديك

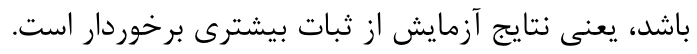

زمان اجرا: زمان لازم براى اجراى الكوريتمهاى كاهش

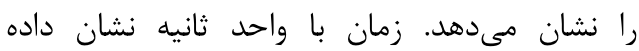
مىشود. شاخص Kappa: اين شاخص براى اندازمكيرى ميزان

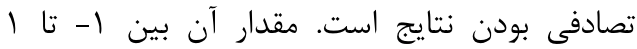
متغير است كه مقدار صفر نشاندهنده تصادفىبودن

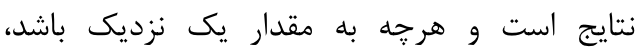
احتمال تصادفىبودن نتايج كمتر است [1].

Kappa $=\frac{n \sum_{i=1}^{c} x_{i i}-\sum_{i=1}^{c} x_{i}, x_{i}}{n^{2}-\sum_{i=1}^{c} x_{i} x_{i}}$

در فرمول (Y)، تعدii

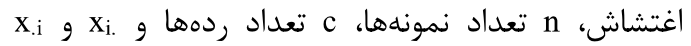
ستونها و سطرهاى تعداد كل هستند.

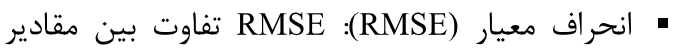
ييشبينىشده با ردهبند براى دادهاى كاهشيافته و نتايج واقعى را نشان مىدهد [37]. درواقع، RMSE خطاهاى بيشبينى ردمبند را نشان مى دهد. RMSE يك تخمين بلهورت زير تعريف مىشود:

$\operatorname{RMSE}(\hat{\theta})=\sqrt{\operatorname{MSE}(\hat{\theta})}=\sqrt{\mathrm{E}\left((\hat{\theta}-\theta)^{2}\right)}$.

جدول (r) نتايج مجموعهداده MNIST را نشان مىدهد. همانَّونه كه در جدول ديده مىشود، الكوريته ReliefF All k- تفاوت زيادى با مجموعه داده اوليه ندارد. همرجنين

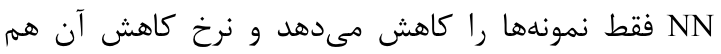

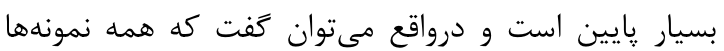
حفظ شدهاند. البته دقت ردهبندى اين الكوريتم بالاتر از

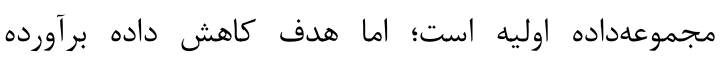

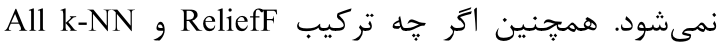

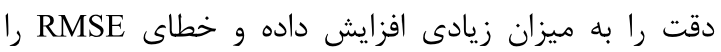

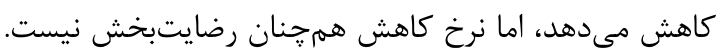
علاوهبراين، زمان اجراى هر سه الكوريته يادشده، بهويزه تركيب ReliefF و All k-NN بسيار بيشتر از الكوريتم IFSB-ReliefF كمتربودن آن حتى از ReliefF اوليه، استفاده از ساخت ساختار

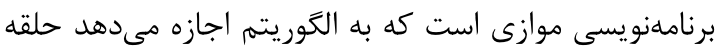

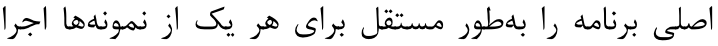

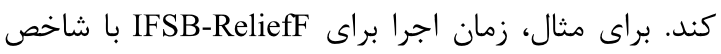

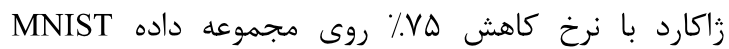


MNIST جدول - (r): نتايج اعمال الخوريتمهاى كاهش داده بر مجموعهداده

(Table-3): The results of applying data reduction algorithms on MNIST data set.

\begin{tabular}{|c|c|c|c|c|c|c|c|}
\hline Kappa & RMSE & زمان اجرا & دقت & تعداد ويزگى باقى مانده & تعداد نمونه & نرخ كاهش & الكوريته كاهش داده \\
\hline 0.8503 & 0.1575 & - & 86.53 & 784 & 50000 & $0 \%$ & Original data set \\
\hline 0.6023 & 0.1567 & 34975 & 86.73 & 392 & 50000 & $50 \%$ & Relieff \\
\hline 0.8643 & 0.1499 & 61320 & 87.80 & 784 & 48843 & $2.31 \%$ & All k-NN \\
\hline 0.4802 & 0.1463 & 94623 & 88.45 & 392 & 48843 & $51.15 \%$ & All k-NN+ ReliefF \\
\hline 0.8341 & 0.1657 & 8671 & 85.07 & 392 & 25000 & $75 \%$ & $\begin{array}{c}\text { IFSB-ReliefF with } \\
\text { Jaccard Index }\end{array}$ \\
\hline 0.7962 & 0.1898 & 8649 & 80.49 & 235 & 15000 & $91 \%$ & $\begin{array}{c}\text { IFSB-ReliefF with } \\
\text { Jaccard index }\end{array}$ \\
\hline 0.8374 & 0.1634 & 8237 & 85.38 & 392 & 25000 & $75 \%$ & $\begin{array}{l}\text { IFSB-ReliefF with } \\
\text { Manhattan distance }\end{array}$ \\
\hline 0.8252 & 0.1708 & 8313 & 84.27 & 235 & 15000 & $91 \%$ & $\begin{array}{l}\text { IFSB-ReliefF with } \\
\text { Manhattan distance }\end{array}$ \\
\hline
\end{tabular}

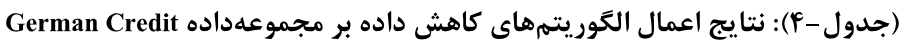

(Table-4): The results of applying data reduction algorithms on German Credit data set

\begin{tabular}{|c|c|c|c|c|c|c|c|}
\hline Kappa & RMSE & زمان اجرا & دق & تعداد ويزگگ باقى مانده & تعداد نمونههاى & كاهش & الخوريتم كاهش داده \\
\hline 0.2687 & 0.4836 & - & 72.65 & 20 & 1000 & $0 \%$ & Original data set \\
\hline 0.284 & 0.4221 & 1 & 74.70 & 10 & 1000 & $50 \%$ & ReliefF \\
\hline 0.3737 & 0.298 & 2 & 90.29 & 20 & 698 & $30.2 \%$ & All k-NN \\
\hline 0 & 0.3329 & 2.8 & 87.34 & 10 & 698 & $65.1 \%$ & All k-NN+ ReliefF \\
\hline 0.2793 & 0.4574 & 44.7 & 71.76 & 10 & 500 & $75 \%$ & $\begin{array}{l}\text { IFSB-ReliefF with } \\
\text { Jaccard Index }\end{array}$ \\
\hline 0.4344 & 0.4031 & 44.3 & 76.47 & 7 & 300 & $89.5 \%$ & $\begin{array}{l}\text { IFSB-ReliefF with } \\
\text { Jaccard index }\end{array}$ \\
\hline 0.5921 & 0.3639 & 112.5 & 84.12 & 10 & 500 & $75 \%$ & $\begin{array}{l}\text { IFSB-ReliefF with } \\
\text { Manhattan distance }\end{array}$ \\
\hline 0.7414 & 0.3067 & 112.4 & 89.21 & 7 & 300 & $89.5 \%$ & $\begin{array}{l}\text { IFSB-ReliefF with } \\
\text { Manhattan distance }\end{array}$ \\
\hline
\end{tabular}

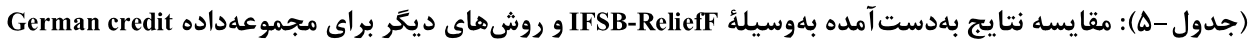

(Table-5): Comparison between results obtained by IFSB-ReliefF and other methods for German credit

\begin{tabular}{|c|c|c|c|c|c|}
\hline Kappa & زمان اجرا(ثانيه) & دقت & تعداد ويزگگىها & تعداد نمونهها & الكوريتم كاهش داده \\
\hline 0.2335 & 555.26 & 71.8 & - & - & IFS-CoCo [1] \\
\hline- & - & 69.2 & 8 & 55 & GA:FSIS [30] \\
\hline- & - & 67.2 & 6 & 210 & GA:ISFS [30] \\
\hline 0.178 & 44.7 & 66.2 & 10 & 500 & $\begin{array}{l}\text { IFSB-ReliefF with } \\
\text { Jaccard Index }\end{array}$ \\
\hline 0.3369 & 44.3 & 71 & 7 & 300 & $\begin{array}{l}\text { IFSB-ReliefF with } \\
\text { Jaccard index }\end{array}$ \\
\hline 0.194 & 112.5 & 66.6 & 10 & 500 & $\begin{array}{l}\text { IFSB-ReliefF with } \\
\text { Manhattan distance }\end{array}$ \\
\hline 0.2295 & 112.4 & 68.67 & 7 & 300 & $\begin{array}{l}\text { IFSB-ReliefF with } \\
\text { Manhattan distance }\end{array}$ \\
\hline
\end{tabular}

الكوريتم קيشنهادى كمتر بوده و فقط ويزگىها را كاهش

مىدهد. همرجنين، All k-NN با زمان اجراى كمترى نسبت

به IFSB-ReliefF به نتايجى با دقت بالا (حتى دقيقتر از
جدول (9) نتايج را براى مجموعهداده Census نشان

مىدهد. اگرجه ReliefF براى كاهش داده زمان كمى صرف

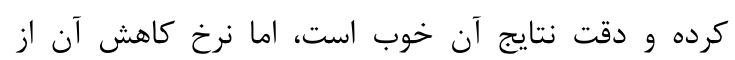


بيشترى عمل كرده است. البته اين الكوريته زمان بيشترى

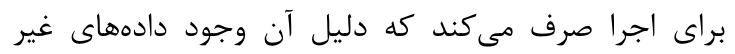

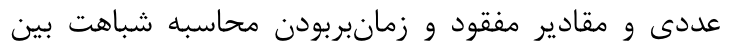

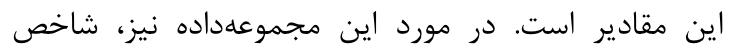
زاكارد زمان كمترى براى كاهش داده مصرف كرده است، اما در شاخصهاى ردهبندى عملكرد ضعيفترى از فاصله منهتن داشته است.
مجموعهداده اوليه) مىرسد، اما نرخ كاهش ان بسيار پايين بوده و درعمل به هدف كاهش دادهها دست نمى ديابد.

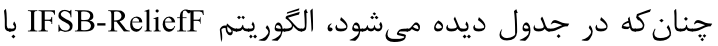

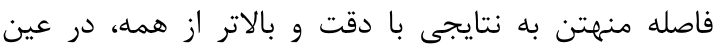

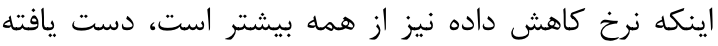

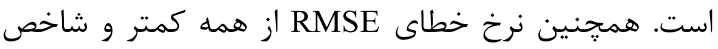
Kappa

(جدول - (9): نتايج اعمال الكَريتهمهاى كاهش داده بر مجموعهداده Census

(Table-6): The results of applying data reduction algorithms on Census dataset.

\begin{tabular}{|c|c|c|c|c|c|c|c|}
\hline Kappa & RMSE & اجرا(ثانيه) & دقت & وبرَّى هاى & نمونهداى & نرخ كاهش & الكوريتم كاهش داده \\
\hline 0.4604 & 0.1963 & - & 95.47 & 41 & 30000 & $0 \%$ & Original data set \\
\hline 0.3707 & 0.2037 & 490 & 94.98 & 20 & 30000 & $52 \%$ & ReliefF \\
\hline 0.7202 & 0.0835 & 2396 & 99.23 & 41 & 28377 & $5.41 \%$ & All k-NN \\
\hline 0.4302 & 0.0954 & 2832 & 99.06 & 20 & 28377 & $53 \%$ & All k-NN+ ReliefF \\
\hline 0.239 & 0.2245 & 7098 & 94.13 & 21 & 15000 & $75 \%$ & $\begin{array}{l}\text { IFSB-ReliefF with Jaccard } \\
\text { Index }\end{array}$ \\
\hline 0.2375 & 0.2131 & 7017 & 94.50 & 13 & 9000 & $90.48 \%$ & $\begin{array}{l}\text { IFSB-ReliefF with Jaccard } \\
\text { index }\end{array}$ \\
\hline 0.9375 & 0.0946 & 11529 & 99.05 & 21 & 15000 & $75 \%$ & $\begin{array}{l}\text { IFSB-ReliefF with } \\
\text { Manhattan distance }\end{array}$ \\
\hline 0.9084 & 0.0788 & 11201 & 99.31 & 13 & 9000 & $90.48 \%$ & $\begin{array}{l}\text { IFSB-ReliefF with } \\
\text { Manhattan distance }\end{array}$ \\
\hline
\end{tabular}

(جدول - Balance-scale نتايج اعمال الكَوريتمهاى كاهش داده بر مجموعهداده

(Table-7): The results of applying data reduction algorithms on Balance-scale data set

\begin{tabular}{|c|c|c|c|c|c|c|c|}
\hline Kappa & RMSE & اجرا(ثانيه) & دقت & باقى ماندَّى هاى & نمونه تعاد & نرخ كاهش & الكوريتم كاهش داده \\
\hline 0.5495 & 0.3651 & & 74.057 & 4 & 625 & $0 \%$ & Original data set \\
\hline 0.3511 & 0.3978 & 0.9 & 64.62 & 2 & 625 & $50 \%$ & ReliefF \\
\hline 0.7496 & 0.3373 & 1 & 87.5 & 4 & 565 & $9.6 \%$ & All k-NN \\
\hline 0.4701 & 0.4317 & 1.7 & 73.44 & 2 & 565 & $54.8 \%$ & All k-NN+ ReliefF \\
\hline 0.2163 & 0.4269 & 5.15 & 56.60 & 2 & 313 & $74.96 \%$ & $\begin{array}{l}\text { IFSB-ReliefF with Jaccard } \\
\text { Index }\end{array}$ \\
\hline 0.2149 & 0.4128 & 5.45 & 54.69 & 1 & 187 & $92.52 \%$ & $\begin{array}{l}\text { IFSB-ReliefF with Jaccard } \\
\text { index }\end{array}$ \\
\hline 0.5972 & 0.345 & 1.6 & 78.302 & 2 & 313 & $74.96 \%$ & $\begin{array}{l}\text { IFSB-ReliefF with } \\
\text { Manhattan distance }\end{array}$ \\
\hline 0.6007 & 0.3485 & 2.2 & 78.125 & 1 & 187 & $92.52 \%$ & $\begin{array}{l}\text { IFSB-ReliefF with } \\
\text { Manhattan distance }\end{array}$ \\
\hline
\end{tabular}


(جدول-^): مقايسه نتايج بهدست آمده توسط IFSB-ReliefF و روشهاى ديخر براى مجموعهداده Balance-scale

(Table-8): Comparison between results obtained by IFSB-ReliefF and other methods for Balance-scale

\begin{tabular}{|c|c|c|c|c|c|}
\hline Kappa & زمان اجرا(ثانيه) & دقت & تعداد ويثگى ها & تعداد نمونهها & الكَوريتم كاهش داده \\
\hline 0.7578 & 69.58 & 84.95 & - & - & IFS-CoCo [1] \\
\hline- & - & 72.70 & 3 & 68 & GA:FSIS [30] \\
\hline- & - & 62.38 & 2 & 28 & GA:ISFS [30] \\
\hline 0.1361 & 5.15 & 53.35 & 2 & 313 & $\begin{array}{l}\text { IFSB-ReliefF with } \\
\text { Jaccard Index } \\
\end{array}$ \\
\hline 0.2871 & 5.45 & 61.49 & 1 & 187 & $\begin{array}{l}\text { IFSB-ReliefF with } \\
\text { Jaccard index }\end{array}$ \\
\hline 0.6391 & 1.6 & 80.511 & 2 & 313 & $\begin{array}{l}\text { IFSB-ReliefF with } \\
\text { Manhattan distance }\end{array}$ \\
\hline 0.5842 & 2.2 & 77.54 & 1 & 187 & $\begin{array}{l}\text { IFSB-ReliefF with } \\
\text { Manhattan distance }\end{array}$ \\
\hline
\end{tabular}

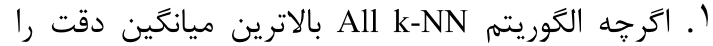

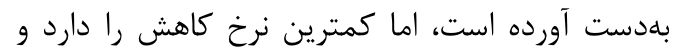

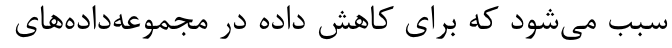

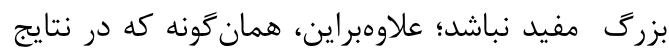

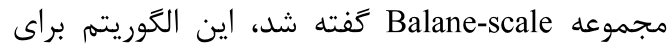

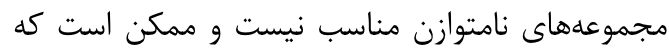

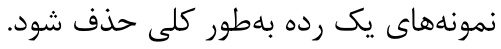

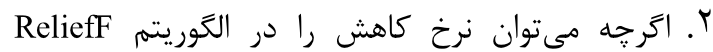

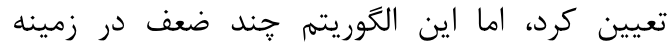

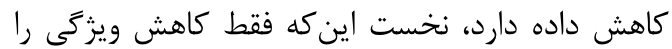

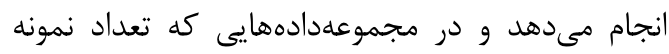

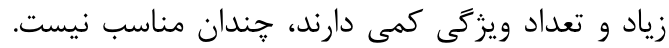

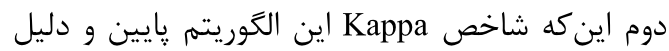

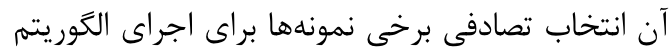

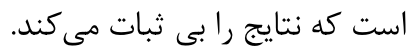

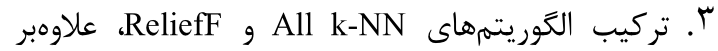
تمام معايب كفتهشده، سبب افزايش بسيار زياد زمان مان

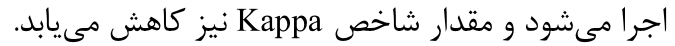

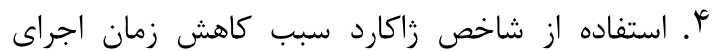

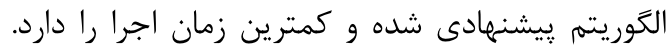

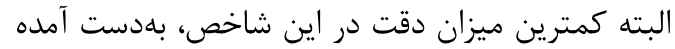

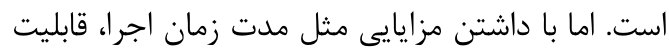

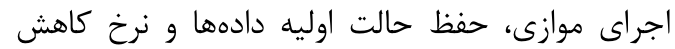

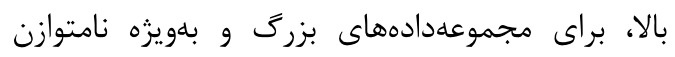
مى تواند يك انتخاب مناسب باشد.

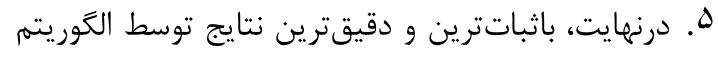
IFSB-ReliefF

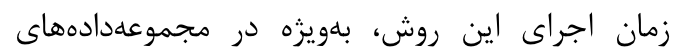
غيرعددى، بيشتر از شاخص زئ زاكارد است؛ بنابراين

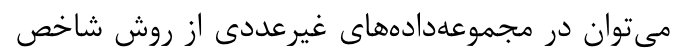
زاكارد و در دادههاى عددى از فاصله فاصله منهتن استفاده
Balance-scale در جدول (V) نتايج مجموعهداده ارائه شده است. همانطور كه مشاهده مىشود، بالاترين

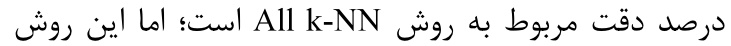

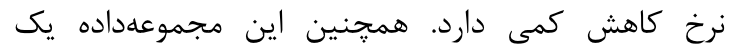

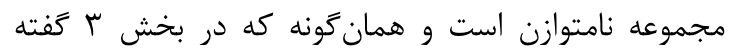

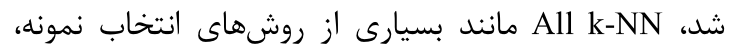

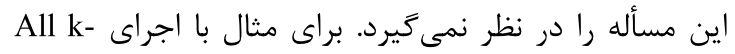

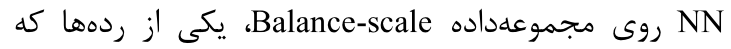

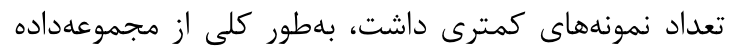

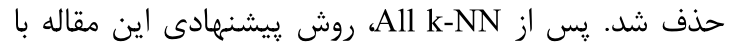

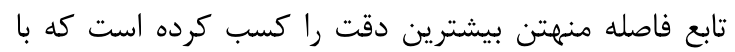

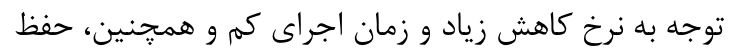

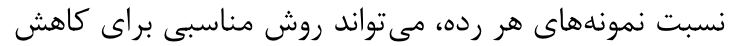

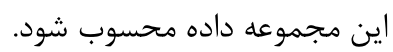

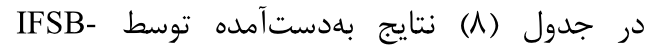
ReliefF با نتايج مقالات [1] و [30] مقايسه شده است.

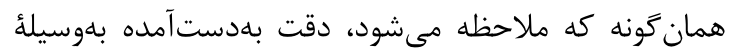

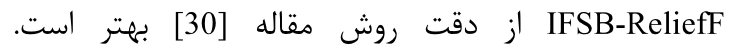

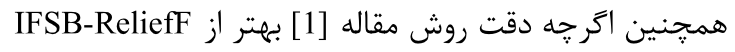

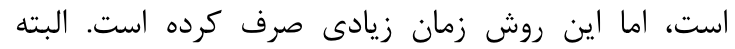

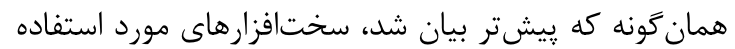

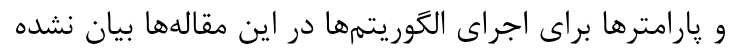

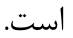

\section{ه- بحث و يافته هاى يزوهش}

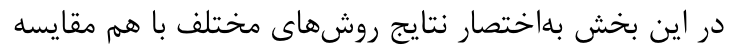

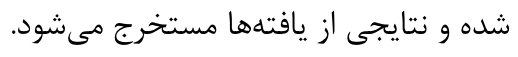

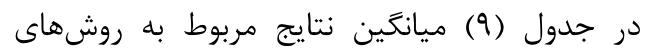

$$
\text { مختلف مشاهده مىشود. }
$$

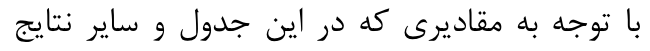

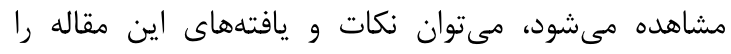

$$
\text { بهصورت زير خلاصه كرد: }
$$




\begin{tabular}{|c|c|c|c|c|c|}
\hline \multicolumn{6}{|c|}{$\begin{array}{l}\text { (جدول-9): ميانگين نتايج مربوط به الخوريتمهاى مختلف (Table-9): The average of results for various algorithms } \\
\text { (ج) }\end{array}$} \\
\hline Kappa & RMSE & اجران إنانيه) & دقت & نرخ كاهش & الكوريتم كاهش داده \\
\hline 0.5322 & 0.3006 & - & 82.18 & $0 \%$ & Original data set \\
\hline 0.4020 & 0.2951 & 8867 & 80.26 & $51 \%$ & ReliefF \\
\hline 0.6770 & 0.2172 & 15930 & 91.21 & $12 \%$ & All k-NN \\
\hline 0.3451 & 0.2516 & 24365 & 87.07 & $56 \%$ & All k-NN+ ReliefF \\
\hline 0.3922 & 0.3186 & 3946 & 76.89 & $75 \%$ & $\begin{array}{l}\text { IFSB-ReliefF with Jaccard } \\
\text { Index }\end{array}$ \\
\hline 0.4208 & 0.3047 & 3921 & 76.54 & $91 \%$ & $\begin{array}{l}\text { IFSB-ReliefF with Jaccard } \\
\text { index }\end{array}$ \\
\hline 0.7411 & 0.2417 & 4952 & 86.71 & $75 \%$ & $\begin{array}{l}\text { IFSB-ReliefF with } \\
\text { Manhattan distance }\end{array}$ \\
\hline 0.7689 & 0.2262 & 4889 & 87.73 & $91 \%$ & $\begin{array}{l}\text { IFSB-ReliefF with } \\
\text { Manhattan distance }\end{array}$ \\
\hline
\end{tabular}

مجموعهدادههاى مختلف آزمايش و همرجنين نتايج حاصل از

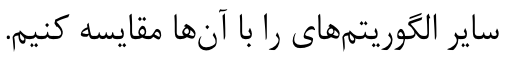

\section{7- References}

$$
\text { - مراجع }
$$

[1] J. Derrac, S. Garcia and F. Herrera, "IFS-CoCo: Instance and feature selection based on cooperative coevolution with nearest neighbor rule.," Pattern Recognition, vol. 43, no. 6, pp. 2082-2105, 2010.

[2] H. Liu and L. Yu, "Toward Integrating Feature Selection Algorithms for Classification and Clustering," Knowledge and Data Engineering, IEEE Transactions on, vol. 17, no. 4, pp. 491502, 2005.

[3] V. Bolón-Canedo, N. Sánchez-Maroño and A. Alonso-Betanzos, "Recent advances and emerging challenges of feature selection in the context of big data," Knowledge-Based Systems, vol. 86, pp. 33-45, 2015.

[4] L. C. Molina, L. Belanche and À. Nebot, "Feature Selection Algorithms: A Survey and Experimental Evaluation," in IEEE International Conference on Data Mining, 2002.

[ه] ج . يورامينى ,ب .مينايى بيدگلى و م .اسماعيلى ,

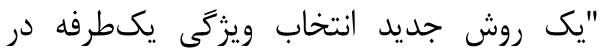

دستهبندى دادهاى متنى نامتوازن، ",يردازش

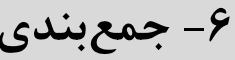

رشد بعرويه دادها و وجود دادههاى تكرارى و داراى نوفه، نهتنها نياز به دستكاههاى ذخيرهسازى عظيم دارد، بلكه دقت

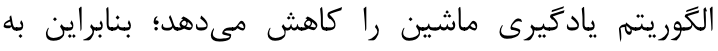
روشهايى براى كاهش دادها و استخر اج اطلاعات مفيد نياز

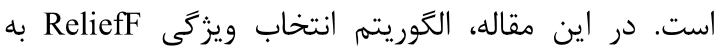
روشى متفاوت استفاده مىشود. در الكوريتم IFSB-ReliefF، مشابهت نمونهها اندازمكيرى شده و نزديكترين نمونهها به

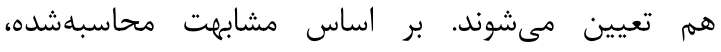

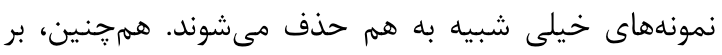
اساس همين مجموعه همسايخى، وزن هر ويزگى محاسبه و

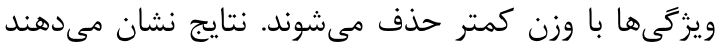

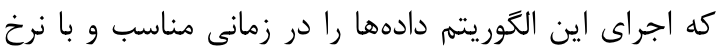
كاهش بالايى كاهش مىدهد؛ علاوهبراين، IFSB-ReliefF مىتواند دقت ردهبندى را در محدوده مجموعهداده اوليه حفظ كرده و در مواردى حتى بهبود بخشد. همجنين، اين

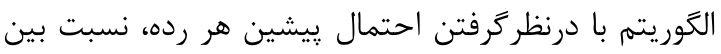

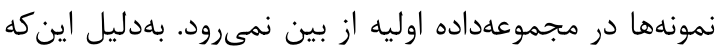
دستورها در حلقه اصلى الخوريتم در تكرارهاى مختلف از هما دماند

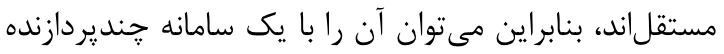

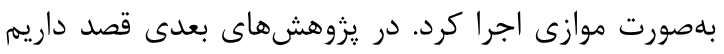

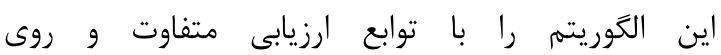


methods based on information entropy," in IEEE International Joint Conference on Neural Networks, 2004.

[20] G. Chandrashekar and F. Sahin, "A survey on feature selection methods," Computers \& Electrical Engineering, vol. 40, no. 1, pp. 16-28, 2014.

[21] I. Kononenko, E. Šimec and M. Robnik-Šikonja, "Overcoming the myopia of inductive learning algorithms with RELIEFF," Applied Intelligence, vol. 7, no. 1, pp. 39-55, 1997.

[22] J. R. Quinlan, C4.5: Programs for Machine Learning, Morgan Kaufmann Publishers, 1993.

[23] L. A. R. Kenji Kira, "The feature selection problem: Traditional methods and a new algorithm," AAAI, vol. 2, pp. 129-134, 1992.

[24] M. Robnik-Šikonja and I. Kononenko, "Theoretical and empirical analysis of ReliefF and RReliefF," Machine learning , vol. 53, no. (1-2), pp. 23-69, 2003.

[25] H. Liu and H. Motoda, Computational methods of feature selection, CRC Press, 2007.

[26] K. Yu, X. Xu, M. Ester and H.-P. Kriegel, "Feature weighting and instance selection for collaborative filtering: An information-theoretic approach," Knowledge and Information Systems, vol. 5, no. 2, pp. 201-224, 2003.

[27] T. Chen, X. Zhang, S. Jin and O. Kim, "Efficient classification using parallel and scalable compressed model andits application on intrusion detection," Expert Systems with Applications, vol. 41, pp. 5972-5983, 2014.

[28] W. T, Hadoop, The Definitive Guide, O'Reilly Media, Inc., 2012.

[29] P. Perner, "Prototype-based classification," Applied Intelligence, vol. 28, no. 3, pp. 238-246, 2008.

[30] C.-F. Tsai, W. Eberle and C.-Y. Chu, "Genetic algorithms in feature and instance selection," Knowledge-Based Systems, vol. 39, p. 240-247, 2013.

[31] F. Dimitris, D. Meretakis and L. Spiros, "Integrating Feature and Instance Selection for text classification," In Proceedings of the eighth ACM SIGKDD international conference on Knowledge discovery and data mining, 2002.

[32] H. Ahn and K.-j. Kim, "Bankruptcy prediction modeling with hybrid case-based reasoning and genetic algorithms approach," Applied Soft Computing, vol. 9, no. 2, pp. 599-607, 2009.

[33] Z. Abbasi and M. Rahmani, "An Instance Selection Algorithm Based on ReliefF," International Journal on Artificial Intelligence Tools, vol. 28, no. 1, p. 1950001, 2019.

[34] I. Tomek, "An experiment with the edited nearest-neighbor rule," IEEE Transactions on
[5]

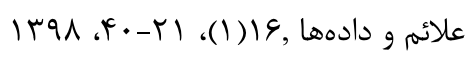

J. Pouramini, B.Minaei-Bidgoli, M.Esmaeili, "A Novel One Sided Feature Selection Method for Imbalanced Text Classification", JSDP, 2019, vol. 16 (1), pp.21-40.

[6] P. S. Bradley, U. M. Fayyad and C. Reina, "Scaling clustering algorithms to large databases," in Proceedings of the Fourth International Conference on Knowledge Discovery \& Data Mining, New York, 1998.

[7] H. Liu, H. Motoda and L. Yu, "A selective sampling approach to active feature selection," Artificial Intelligence, vol. 159, pp. 49-74, 2004.

[8] W. Cochran, Sampling Techniques, New York: Wiley, 1977.

[9] H. Liu and H. Motoda, Instance Selection and Construction for Data Mining, Boston,MA: Kluwer Academic, 2001.

[10] S. Garci'a, J. Derrac, J. R. Cano and F. Herrera, "Prototype Selection for Nearest Neighbor Classification: Taxonomy and Empirical Study," IEEE Transactions On Pattern Analysis And Machine Intelligence, vol. 34, no. 3, pp. 417435, MARCH 2012.

[11] S. Garc' 1a, J. Derrac, J. R. Cano and F. Herrera, "Prototype Selection for Nearest Neighbor Classification: Survey of Methods," IEEE Transactions On Pattern Analysis And Machine Intelligence., vol. 34, no. 3, pp. 417-435, 2012.

[12] F. H. M. L. Jose Ramon Cano, "On the combination of evolutionary algorithms and stratified strategies for training set selection in data mining," Applied Soft Computing, vol. 6, pp. 323-332, 2006.

[13] S. d. Río, V. Lopez, J. M. Benítez and F. Herrera, "On the use of MapReduce for imbalanced big data using Random Forest," Information Sciences, vol. 285, pp. 112-137, 2014.

[14] d. Wilson and t. r. Martinez, "Reduction techniques for instance-based learning algorithms," Machine learning, vol. 38, no. 3, pp. 257-286, 2000.

[15] H. Liu and H. Motoda, "On issues of instance selection," Data Mining and Knowledge Discovery, vol. 6, no. 2, pp. 115-130, 2002.

[16] D. R. Wilson and M. Tony R, "Instance pruning techniques," ICML, vol. 97, pp. 403-411, 1997.

[17] p. Jaccard, "Étude comparative de la distribution florale dans une portion des Alpes et des Jura," Bulletin de la Société Vaudoise des Sciences Naturelles, vol. 37, p. 547-579, 1901.

[18] G. H. J. Ron Kohavi, "Wrappers for feature subset selection," Artificial intelligence, vol. 97, no. 1, pp. 273-324, 1997.

[19] W. Duch, T. Wieczorek, J. Biesiada and M. Blachnik, "Comparison of feature ranking 
Systems, Man, and Cybernetics, vol. 6, pp. 448452, 1976.

[35] J. R. Quinlan, "Improved use of continuous attributes in c4.5.," Journal of Artificial Intelligence Research, vol. 4, pp. 77-90, 1996.

[36] I. Triguero, D. Peralta, J. Bacardit, S. García and F. Herrera, "MRPR: A MapReduce solution for prototype reduction in big data classification," Neurocomputing, vol. 150, pp. 331-345, 2015.

[37] R. Hyndman and K. Anne B., "Another look at measures of forecast accuracy," International Journal of Forecasting, vol. 22, no. 4, pp. 679688, 2006.

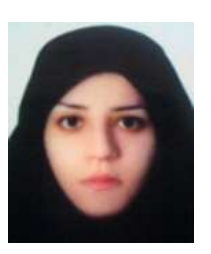

$$
\begin{aligned}
& \text { زينب عباسى. دكتراى خود را در رشته } \\
& \text { مهندسى نرمافزار در دانشعاه اراك در سال }
\end{aligned}
$$

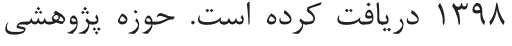

$$
\begin{aligned}
& \text { ايشان، دادهاوى و الخوريتمهاى كاهش دري } \\
& \text { داده است. } \\
& \text { نشانى رايانامه ايشان عبارت است از: }
\end{aligned}
$$

Zabasi@gmail.com

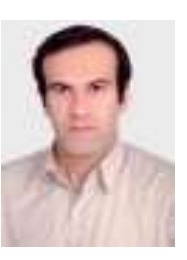

$$
\begin{aligned}
& \text { محسن رحمانى. مدرك دكتراى خود را }
\end{aligned}
$$

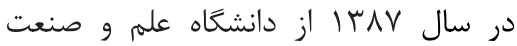

$$
\begin{aligned}
& \text { ايران دريافت كردند. ايشان همماكنون عضو }
\end{aligned}
$$

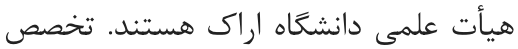

$$
\begin{aligned}
& \text { ايشان زيردازش سيگنالهاى صوتى و هوش } \\
& \text { مصنوعى است. } \\
& \text { نشانى رايانامه ايشان عبارت است ازي: }
\end{aligned}
$$

m-rahmani@araku.ac.ir

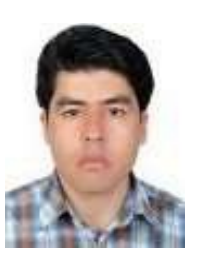

$$
\begin{aligned}
& \text { حسين غفاريان. دكتراى خود را از } \\
& \text { دانشعاه علم و صنعت ايران در سال بوسئ } \\
& \text { دريافت كردند و در حال حاضر عضو هيأت } \\
& \text { علمى دانشعاه اراى هستند. حوزه تخصصى درى درى } \\
& \text { فعاليت ايشان دادهاوى و والگوريتمهاى } \\
& \text { تكاملى است. } \\
& \text { نشانى رايانامه ايشان عبارت است ازئ }
\end{aligned}
$$

H-ghaffarian@araku.ac.ir 
